\title{
Differential internalization of amphotericin B - Conjugated nanoparticles in human cells and the expression of heat shock protein 70
}

\author{
Cristiana S.O. Paulo ${ }^{\mathrm{a}, \mathrm{b}, 1}$, Miguel M. Lino ${ }^{\mathrm{a}, \mathrm{c}, 1}$, António A. Matos ${ }^{\mathrm{d}, \mathrm{e}}$, Lino S. Ferreira ${ }^{\mathrm{a}, \mathrm{b}, *}$ \\ ${ }^{a}$ CNC-Center for Neurosciences and Cell Biology, University of Coimbra, 3004-517 Coimbra, Portugal \\ ${ }^{\mathrm{b}}$ Biocant, Biotechnology Innovation Center, 3060-197 Cantanhede, Portugal \\ ${ }^{c}$ Matera, Biocant, Biotechnology Innovation Center, 3060-197 Cantanhede, Portugal \\ ${ }^{\mathrm{d}}$ Serviço de Microscopia Electrónica, Hospital Curry Cabral, Lisboa, Portugal \\ ${ }^{\text {e }}$ Centre for Environmental and Marine Studies (CESAM), Aveiro University, Aveiro, Portugal
}

\section{A R T I C L E I N F O}

\section{Article history:}

Received 30 January 2013

Accepted 15 March 2013

Available online 8 April 2013

\section{Keywords:}

Silica nanoparticles

Antifungal

Amphotericin B

Heat shock protein

Cytotoxicity

\begin{abstract}
A B S T R A C T
Although a variety of nanoparticles (NPs) functionalized with amphotericin B, an antifungal agent widely used in the clinic, have been studied in the last years their cytotoxicity profile remains elusive. Here we show that human endothelial cells take up high amounts of silica nanoparticles (SNPs) conjugated with amphotericin B (AmB) (SNP-AmB) (65.4 \pm 12.4 pg of Si per cell) through macropinocytosis while human fibroblasts internalize relatively low amounts $(2.3 \pm 0.4 \mathrm{pg}$ of $\mathrm{Si}$ per cell) because of their low capacity for macropinocytosis. We further show that concentrations of SNP-AmB and SNP up to $400 \mu \mathrm{g} / \mathrm{mL}$ do not substantially affect fibroblasts. In contrast, endothelial cells are sensitive to low concentrations of NPs (above $10 \mu \mathrm{g} / \mathrm{mL}$ ), in particular to SNP-AmB. This is because of their capacity to internalize high concentration of NPs and high sensitivity of their membrane to the effects of AmB. Low-moderate concentrations of SNP-AmB (up to $100 \mu \mathrm{g} / \mathrm{mL}$ ) induce the production of reactive oxygen species (ROS), LDH release, high expression of pro-inflammatory cytokines and chemokines (IL-8, IL-6, G-CSF, CCL4, IL-1 $\beta$ and CSF2) and high expression of heat shock proteins (HSPs) at gene and protein levels. High concentrations of SNP-AmB (above $100 \mu \mathrm{g} / \mathrm{mL}$ ) disturb membrane integrity and kill rapidly human cells (60\% after $5 \mathrm{~h}$ ). This effect is higher in SNP-AmB than in SNP.
\end{abstract}

(c) 2013 Elsevier Ltd. All rights reserved.

\section{Introduction}

AmB is a potent antifungal agent, approved by the FDA, widely used in clinical practice and effective against a large spectrum of fungi. Few resistant strains of fungi to AmB have been reported so far [1]. Experimental data indicates that $A m B$ associates with the ergosterol in the fungal cell membrane, forming pores and consequently disrupting the ionic gradient [2]. Due to these properties, $\mathrm{AmB}$ has been permanently immobilized in hydrogels $[3,4]$ and nanomaterials (silica and carbon nanotubes) [5-7]. The nanoformulations have been used to create permanent coatings [7] and as substitutes of commercial lipid-based nanoformulations of AmB $[5,6]$. The competitive advantages of AmB immobilized onto

\footnotetext{
* Corresponding author. Biocant, Biotechnology Innovation Center, Núcleo 4, Lote 3, 3060-197 Cantanhede, Portugal.

E-mail address: lino@biocant.pt (L.S. Ferreira).

1 Cristiana S. O. Paulo and Miguel M. Lino contributed equally to this work.
}

nanomaterials relatively to lipid-based formulations are ascribed to (i) increased stability of the AmB nanomaterial conjugate, (ii) potential decrease in the concentration required for therapeutic use (due to the immobilization of high doses of agent at the surface of the nanomaterial), and (iii) the possibility of incorporating ligands to target specific tissues. Unfortunately, it is relatively unknown the cytotoxic profile of AmB nanomaterials conjugates.

Previous studies have shown that cellular toxicity of AmB was higher when associated with low-density lipoprotein (LDL) [8,9]. However, it is unclear whether the toxicity effect is mediated by an interaction of $\mathrm{AmB}$ with cell membrane or requires the intracellular delivery of AmB. Further, although several experimental results indicate that the toxicity of $\mathrm{AmB}$ is due to its ability to induce oxidative stress and disturb normal ion functioning [2,10,11], it is unclear whether both mechanisms occur at the same time or are dependent on the concentrations of AmB.

In this work, we hypothesize that the cytotoxic effect of AmB is dependent on cell type and it depends on the initial concentration of the NPs. To verify this hypothesis we have evaluated the 
cytotoxicity profile of AmB conjugated to SNPs [7] in human umbilical vein endothelial cells (HUVECs) and fibroblasts. We have studied the uptake mechanism and intracellular fate of the NPs with and without AmB and their effect in cell metabolic activity and proliferation. Further, we have quantified cell membrane integrity, oxidative stress, and apoptosis on cells treated with SNPs with and without AmB. Finally, we have quantified the expression of stress and toxicity genes and quantified the secretion of cytokines.

\section{Materials and methods}

\subsection{Conjugation of SNPs with DexOx and DexOxAmB}

SNP5 were kindly offered by Eka (Sweden), while SNP80 were purchased from PlasmaChem GmbH (Germany). Either SNP5 or SNP80 used in the entire work were from the same batch. The silanization, conjugation of AmB (Applichem GmbH, Germany) to the NPs and NPs characterization was performed according to protocols previously reported by us [7]. Endotoxin levels in the nanoparticle suspension $(50 \mu \mathrm{g} / \mathrm{mL}$ ) were detected using a Limulus assay kit (Lonza) and found to be below $0.125 \mathrm{EU} / \mathrm{mL}$, the acceptable levels of endotoxins for pharmaceutical formulations [12].

\subsection{Cell culture}

Primary human skin fibroblasts (Lonza) were grown in DMEM supplemented with $10 \%$ fetal bovine serum (FBS), at $37{ }^{\circ} \mathrm{C}$ in a fully humidified air containing $5 \%$ $\mathrm{CO}_{2}$. The cells were fed every 2-3 days. HUVECs (Lonza) were cultured in EGM-2 media (Lonza; containing $2 \%$ of FBS) being the medium replaced every 2 days. Both cells were passaged after reaching $80 \%$ confluency. Cells between the 3 rd and 7 th passages were used in the entire work.

\subsection{NP uptake by FACS analysis}

Fluorescent-labeled SNPs were obtained by reacting DexOx or DexOxAmB with fluoresceinamine or by reacting the terminal amine groups in SNPs with fluorescein isothiocyanate (FITC). In the first case, DexOx $(250 \mathrm{mg})$ was reacted with flouresceinamine $(26.7 \mu \mathrm{g})$ in a $1: 1 \mathrm{mixture}$ of $0.01 \mathrm{~m}$ borate buffer $\mathrm{pH} 10$ with DMSO $(12 \mathrm{~mL})$. The reaction was allowed to proceed for $18 \mathrm{~h}$ and the conjugate was then dialyzed against distilled water in a 6-8 kDa MWCO membrane for 2 days. The conjugates were then freeze-dried. Fluorescent DexOxAmB was prepared in a similar manner, being AmB (213 mg) added to the reaction mix. To prepare fluorescent SNPs (without DexOx or DexOxAmB), we reacted SNP5- $\mathrm{NH}_{2}(100 \mathrm{mg}$ ) with FITC $(19.5 \mu \mathrm{g})$ or SNP80- $\mathrm{NH}_{2}(100 \mathrm{mg})$ with FITC $(24 \mu \mathrm{g})$ in $0.01 \mathrm{~m}$ borate buffer $\mathrm{pH}$ $10(12.5 \mathrm{~mL})$ with magnetic stirring for $18 \mathrm{~h}$. Unbound FITC was removed by centrifugation and washing of the NP with distilled water.

HUVECs or fibroblasts were plated in gelatin-coated 24 well plates $\left(1 \times 10^{5}\right.$ cells/ well). After $18 \mathrm{~h}$, the cells were incubated with SNP5- $\mathrm{NH}_{2}-\mathrm{FITC}$, SNP80- $\mathrm{NH}_{2}-$ FITC, SNP5-DexOx-fluoresceinamine, SNP80-DexOx-fluoresceinamine, SNP5-DexOxAmB-fluoresceinamine or SNP80-DexOxAmB-fluoresceinamine (all at $50 \mu \mathrm{g} / \mathrm{mL}$ ) suspended in cell culture medium (i.e., DMEM supplemented with $10 \%$ FBS in case of fibroblasts and EGM-2 containing 2\% of FBS for HUVECs). After 5 or $24 \mathrm{~h}$, the cells were washed with PBS, dissociated with trypsin $(0.2 \% \mathrm{w} / \mathrm{v}$, in PBS) and treated with an aqueous solution of trypan blue $(0.4 \%, \mathrm{w} / \mathrm{v})$ in order to quench the fluorescence of NPs that were not taken up by the cells [13]. Samples were then washed twice (300 g, 2 min) with PBS and analyzed on a FACScalibur (Becton Dickison) using CellQuest software.

For the tests in the presence of endocytosis inhibitors, HUVEC were seeded on 24 well plates $\left(3 \times 10^{4}\right.$ cells/well $)$ and left for $24 \mathrm{~h}$ before starting the test. The following inhibitors were tested: filipin III (HUVEC: $5 \mu \mathrm{g} / \mathrm{mL}$, fibroblasts: $1 \mu \mathrm{g} / \mathrm{mL}, 30 \mathrm{~min}$ preincubation), cytochalasin D (HUVEC: $1 \mu \mathrm{m}$, fibroblasts: $0.5 \mu \mathrm{m}, 120 \mathrm{~min}$ ), nocodazole (HUVEC: $30 \mu \mathrm{m}$, fibroblasts: $10 \mu \mathrm{m}, 30 \mathrm{~min}$ ), polyinosinic acid (HUVEC: $100 \mu \mathrm{g} / \mathrm{mL}$, fibroblasts: $10 \mu \mathrm{g} / \mathrm{mL}, 30 \mathrm{~min}$ ) and dansylcadaverine (HUVEC: $100 \mu \mathrm{m}$, fibroblasts: $50 \mu \mathrm{m}, 30 \mathrm{~min}$ ). The inhibitor concentrations were based in values reported in the literature and further validate by us to have no cytotoxic effect over the period of the assay ( $5 \mathrm{~h}$ ), as confirmed by us using a propidium iodide (PI) assay. When possible, we further confirmed that the concentration tested was active. For example, dansylcadaverine $(100 \mu \mathrm{M})$ was able to inhibit the internalization of transferrin-FITC conjugate by clathrin-mediated endocytosis in HUVECs (Supplementary Fig. 2B). After the pre-incubation with the inhibitor, SNP5-DexOx or SNP5-DexOxAmB $(50 \mu \mathrm{g} / \mathrm{mL})$ formulations were added to the cells, maintaining the inhibitor concentration. As controls we used cells incubated without NPs and cells incubated with SNP5-DexOx or SNP5-DexOxAmB without inhibitor. After $5 \mathrm{~h}$ incubation with the NPs we washed the cells two times with DMEM with $10 \%$ FBS and one time with PBS before trypsinization. After trypsinization, the cells were centrifuged and the supernatant removed. The cells were resuspended in PBS and kept on ice for immediate analysis by flow cytometry.

\subsection{Inductive coupled plasma mass spectrometry (ICP-MS) analysis}

HUVECs $\left(5 \times 10^{5}\right.$ cells/well $)$ and fibroblasts $\left(3.5 \times 10^{5}\right.$ cells/flask) were plated in 6 well plates and T75 flasks, respectively, and left to adhere overnight. Then the cells were incubated with SNP5-DexOx or SNP5-DexOxAmB $(50 \mu \mathrm{g} / \mathrm{mL})$ for 5 or $24 \mathrm{~h}$. After incubation, in order to remove non-internalized NPs, the cells were washed three times with PBS, dissociated with trypsin $[0.2 \%(\mathrm{w} / \mathrm{v})$ in PBS], centrifuged counted and washed again with PBS. Afterwards, the samples were freeze-dried and the presence of silicon in the samples was evaluated by ICP-MS according to a previous protocol [14]. For this purpose, the samples were digested overnight in the presence of hydrofluoric acid $(0.1 \mathrm{~mL}, 40 \%,(\mathrm{w} / \mathrm{v}))$ and ultrasounds. Then, aqueous nitric acid solution $(9.9 \mathrm{~mL}, 2 \%(\mathrm{w} / \mathrm{v}))$ was added. The samples $(n=3)$ were analyzed by ICP-MS for the quantification of internalized silicon.

\subsection{Cellular uptake of NPs by confocal microscopy}

HUVECs were plated on a gelatin-coated microscope slide ( $\mu$-Slide Angiogenesis, Ibidi, Germany) $\left(1 \times 10^{4}\right.$ cells/well $)$ and fibroblasts were plated on 24 -well plates $\left(5 \times 10^{4}\right.$ cells/well $)$ and left to adhere overnight before adding SNP5- $\mathrm{NH}_{2}-$ FITC, SNP80- $\mathrm{NH}_{2}-\mathrm{FITC}$, SNP5-DexOx-fluoresceinamine, SNP80-DexOx-fluoresceinamine, SNP5-DexOxAmB-fluoresceinamine or SNP80-DexOxAmB-fluoresceinamine (all at $50 \mu \mathrm{g} / \mathrm{mL}$ ) in EGM-2 (HUVECs) or DMEM with $0.5 \%(\mathrm{v} / \mathrm{v}$ ) Pen Strep (fibroblasts). After 5 or $24 \mathrm{~h}$, fibroblasts were washed with PBS, harvested with trypsin and plated on coverslips coated with gelatin. HUVEC were washed three times 5 min with DMEM with 10\% FBS. Endosomes were stained with Lysotracker Red DND-99 (Invitrogen, 1:20 000 in medium) for $20 \mathrm{~min}$, at $37^{\circ} \mathrm{C}$, following the recommendations of the dye manufacturer. Then, cells were fixed with paraformaldehyde $(4 \%(\mathrm{v} / \mathrm{v}))$ for $10 \mathrm{~min}$, at room temperature, and washed two times with PBS. After blocking (PBS solution having $2 \%$ BSA and $2 \%$ FCS) for $30 \mathrm{~min}$, HUVECs were incubated with mouse anti-human CD31 antibody (Dako, dilution 1:50) for 60 min, washed two times with PBS and incubated with Dylight 649 conjugated donkey anti-mouse IgG (BioPortugal, dilution 1:200) for $60 \mathrm{~min}$. Unbound antibody was removed by washing two times with PBS before staining with DAPI (Sigma, $2 \mu \mathrm{g} / \mathrm{mL}$ in PBS) for $10 \mathrm{~min}$. Coverslips were mounted and analyzed by confocal microscopy.

\subsection{Transmission electron microscopy analyses}

HUVECs were exposed to SNP5-NH2, SNP5-DexOx or SNP5-DexOxAmB at $50 \mu \mathrm{g} / \mathrm{mL}$ for $24 \mathrm{~h}$. After incubation, cells were washed three times with EGM-2 medium and fixed with glutaraldehyde $(2.5 \%, \mathrm{v} / \mathrm{v}$, in cacodylate buffer). Secondary fixations were made in $\mathrm{OsO}_{4}(1 \%, \mathrm{v} / \mathrm{v}$, in cacodylate buffer) and in uranyl acetate $(0.5 \%, v / v$, in acetate-acetic acid buffer). The samples were then dehydrated and embedded in Epon-Araldite. Thin sections (79-90 $\mu \mathrm{m})$ of the samples were then analyzed by TEM (JEOL 100SX).

\subsection{Cytotoxicity of SNPs functionalized with DexOxAmB}

Cells $\left(1 \times 10^{4}\right.$ cells/well) were seeded onto a 96-well plate coated with $0.1 \%(\mathrm{w} / \mathrm{v})$ gelatin and left to adhere. The cells were then incubated with NPs (from 10 to $500 \mu \mathrm{g}$ / $\mathrm{mL}$ ) for $5 \mathrm{~h}$ or $24 \mathrm{~h}$. In some cases (LDH assay), the medium was then collected and centrifuged $5 \mathrm{~min}$ at $250 \mathrm{~g}$ to remove NP aggregates and cell debris and then the LDH content of the samples $(n=6)$ was determined using colorimetric assay (TOX-7 kit Sigma). As negative control we used the medium of cells incubated without NPs. For the positive control we removed the medium $(200 \mu \mathrm{L})$ and added Triton X-100 solution ( $20 \mu \mathrm{L}, 0.5 \%$ in water) to the cells. After observing total cell lysis, we added $180 \mu \mathrm{L}$ of the initial medium to the well. We analyzed the medium according to manufacturer's instructions. In other cases, the cells were washed and ATP production measured by a Celltiter-Glo Luminescent Cell Viability Assay (Promega).

For Annexin V/PI assay, HUVECs $\left(1 \times 10^{5}\right.$ cells/well) were seeded onto a 24 -well plate coated with $0.1 \%(\mathrm{w} / \mathrm{v})$ gelatin and left to adhere. The cells were then incubated with NPs $(10-300 \mu \mathrm{g} / \mathrm{mL})$ for $5 \mathrm{~h}$ or $24 \mathrm{~h}$. After the incubation time, the medium with the detached cells was collected and the adherent cells rinsed with PBS and trypsinized. Both the detached cells and adherent cells were then mixed and the cells were centrifuged for $3 \mathrm{~min}$ at $350 \mathrm{~g}$. The cells were washed with PBS, resuspended in PBS $(100 \mu \mathrm{L})$, and stained with annexin binding buffer (Invitrogen, $200 \mu \mathrm{L}$ containing $2.5 \mu \mathrm{L}$ of Annexin V-FITC conjugate). The cells were incubated in the dark at room temperature for $10 \mathrm{~min}$ and then on ice before analysis in the flow cytometer. To stain the dead cells, PI $(10 \mu \mathrm{L}, 100 \mu \mathrm{g} / \mathrm{mL})$ was added shortly before running each sample $(n=3)$.

\subsection{Cell proliferation in the presence of SNP-DexOx and SNP-DexOxAmB}

HUVECs or fibroblasts were plated in gelatin-coated 24 well plates $\left(5 \times 10^{4}\right.$ cells well). After $18 \mathrm{~h}$, the cells were incubated with SNP5-DexOx, SNP80-DexOx, SNP5DexOxAmB or SNP80-DexOxAmB at 50 or $100 \mu \mathrm{g} / \mathrm{mL}$. After $24 \mathrm{~h}$, the cells were washed with PBS, harvested with trypsin (0.2\% in PBS) and counted using a Neubauer chamber. Cells without NPs were used as controls for cell number at initial and final incubation times. Each condition was done in triplicate. 


\subsection{Quantification of cellular reactive oxygen species (ROS)}

HUVECs $\left(1 \times 10^{5}\right.$ cells/well $)$ were seeded onto a 24 -well plate coated with $0.1 \%$ $(\mathrm{w} / \mathrm{v})$ gelatin and left to adhere. The cells were then incubated with NPs $(10-300 \mu \mathrm{g} /$ $\mathrm{mL}$ ) for 12 or $24 \mathrm{~h}$. After the incubation time, the medium was collected and kept at $4{ }^{\circ} \mathrm{C}$. In the meantime, the adherent cells were rinsed with PBS and then incubated in serum free medium (Medium 200, Gibco) containing the oxidation-sensitive probe carboxy- $\mathrm{H}_{2}$ DCFDA $(10 \mu \mathrm{M})$ for $1 \mathrm{~h}$ to load the dye in the cells. After this, the serum free medium was replaced with complete medium and the cells were allowed to recover for $2 \mathrm{~h}$. Then, the cells were trypsinized and the medium with the dead cells was added. Cells were centrifuged for $3 \mathrm{~min}$ at $350 \mathrm{~g}$, resuspended in PBS (200 $\mu \mathrm{L})$ and kept on ice before analysis in the flow cytometer. To stain the dead cells, PI $(10 \mu \mathrm{L}, 100 \mu \mathrm{g} / \mathrm{mL})$ was added shortly before running each sample $(n=3)$. As negative control we used cells incubated without NP or with SNP5-DexOx.

\subsection{Real-time RT-PCR array}

HUVECs were seeded in 6 -well plates $\left(1.5 \times 10^{6}\right.$ distributed by 3 wells $)$ and incubated for $24 \mathrm{~h}$ with SNP5-DexOx or SNP5-DexOxAmB $(50 \mu \mathrm{g} / \mathrm{mL})$. Cells without NPs were used as control. After incubation, cells were trypsinized and total RNA was isolated using a protocol with TRIzol (Invitrogen) and RNeasy Minikit (Qiagen, Valencia). cDNA was prepared from $1 \mu \mathrm{g}$ total RNA using the RT ${ }^{2}$ PCR Array first strand kit (SABiosciences), according to the manufacturer's instructions. RT-PCR assays were performed using the human stress and toxicity pathway finder RT-PCR array (SA Biosciences) on an ABI PRISM 7500 System. Data analysis was performed using analysis software provided by the kit manufacturer.

\subsection{Cytokine secretion analyses}

HUVECs and fibroblasts were incubated with medium containing SNP5-DexOx or SNP5-DexOxAmB $(50 \mu \mathrm{g} / \mathrm{mL})$ for 5 or $24 \mathrm{~h}$. The media was then collected and centrifuged to remove potential cells and NPs. Supernatants were evaluated for the presence and concentrations of cytokines using a Bio-Plex Pro Human Cytokine 17Plex Panel Assay (Bio-Rad, Hercules, CA, USA) according to manufacturer's instructions, in a Bio-Plex 200 System (Bio-Rad). The human Group I 17-Plex Pane consisted of the following analytes: interleukin-1 $\beta$ (IL-1 $\beta$ ), IL-2, IL-4, IL-5, IL-6, IL-7, IL-8; IL-10, IL-12(p70), IL-13, IL-17, granulocyte colony-stimulating factor (G-CSF), granulocyte/macrophage colony-stimulating factor (GM-CSF), interferon- $\gamma$ (IFN- $\gamma$ ), monocyte chemotactic protein monocyte chemotactic activating factor [MCP-1 (MCAF)], macrophage inflammatory protein- $\beta$ (MIP-1 $\beta$ ) and tumor necrosis factor- $\alpha$ (TNF- $\alpha$ ). A standard range of $0.2-3200 \mathrm{pg} / \mathrm{mL}$ was used. Samples and controls were run in triplicate, standards and blanks in duplicate.

\subsection{Characterization of HSP70 cellular localization by confocal microscopy}

Round glass coverslips were sterilized with $100 \%$ ethanol and UV radiation for $30 \mathrm{~min}$. Then, they were dried, placed in wells of a 24-well plate and coated with $0.1 \%(\mathrm{w} / \mathrm{v})$ gelatin. HUVEC $\left(1 \times 10^{5}\right.$ cells/well $)$ were seeded on the coverslips and allowed to adhere. Cells were incubated with SNP5-DexOx or SNP5-DexOxAmB $(50 \mu \mathrm{g} / \mathrm{mL})$ for 5 and $24 \mathrm{~h}$. Cells incubated without NPs or cells incubated for $3 \mathrm{~h}$ at $42.5^{\circ} \mathrm{C}$ were used as negative and positive controls, respectively. Cells were washed, fixed with $4 \%(\mathrm{v} / \mathrm{v})$ paraformaldehyde in PBS for $15 \mathrm{~min}$ at room temperature, and then washed two times with cold PBS. Permeabilization of the cells was done by incubating $10 \mathrm{~min}$ with PBS containing $0.25 \%$ Triton X-100. The detergent was removed by washing three times with PBS. Before staining, unspecific binding sites were blocked with PBS containing $1 \%$ BSA and $0.3 \mathrm{~m}$ glycine for $30 \mathrm{~min}$. The cells were then incubated with mouse anti-human HSP70 (3A3) antibody (sc-32239, Santa Cruz) (1:50 in PBS containing 1\% BSA) for $1 \mathrm{~h}$ at room temperature. Cells were washed three times with PBS and then incubated for $1 \mathrm{~h}$ in the dark with goat antimouse IgG Cy3 conjugate (Sigma; 1:50 dilution in PBS containing 1\% BSA). Cells were washed three times with PBS and nuclei were stained with DAPI $(1 \mu \mathrm{g} / \mathrm{mL})$ for $5 \mathrm{~min}$.

\subsection{Quantification of total HSP70 protein expression by sandwich ELISA}

HUVEC were seeded on to 6 -well plates $\left(2 \times 10^{5}\right.$ cells/well) coated with $0.1 \%$ $(\mathrm{w} / \mathrm{v})$ gelatin and left to adhere and grow until $80 \%$ confluency (approximately $8 \times 10^{5}$ cells/well). Cells were incubated with NPs $(50 \mu \mathrm{g} / \mathrm{mL})$ for 5 and $24 \mathrm{~h}$. For negative control we used cells incubated without NPs and as positive control cells submitted to heat shock $\left(42.5^{\circ} \mathrm{C}, 3 \mathrm{~h}\right)$. The cells were then rinsed two times with PBS, placed on ice, and lysis buffer $(200 \mu \mathrm{L}$ containing 1 mм EDTA, $0.5 \%$ Triton X-100, $10 \mu \mathrm{g} / \mathrm{mL}$ Leupeptin, $10 \mu \mathrm{g} / \mathrm{mL}$ Pepstatin, $100 \mu \mathrm{g} / \mathrm{mL}$ PMSF, $3 \mu \mathrm{g} / \mathrm{mL}$ Aprotinin in PBS, $\mathrm{pH}$ 7.4) was added to the cells, which were detached from the plate using cell scrapers. The cell lysates $(n=3)$ were analyzed using the DuoSet IC Intracellular ELISA kit for total HSP70 (R\&D Systems) to obtain the amount of HSP70 protein per sample. The results were normalized to the total cell number per sample. This was done by a total DNA quantification in the lysates. We prepared cell lysates from known cell numbers to use as standards. The quantification of DNA was performed using Hoechst dye $(2 \mu \mathrm{g} / \mathrm{mL}$ in TNE Buffer $(10 \mathrm{~mm}$ Tris $\mathrm{pH} 7.5,0.1 \mathrm{M} \mathrm{NaCl}, 10 \mathrm{~mm}$ EDTA)). The Hoechst solution was pipetted into wells of a black 96 -well plate ( $95 \mu \mathrm{L}$ well) and $5 \mu \mathrm{L}$ of standard or sample lysate was added to each well. The plates were read immediately on a Spectra Max Gemini EM microplate reader (Molecular Devices).

\section{Results and discussion}

\subsection{Properties of NPs}

AmB was conjugated to SNPs having an initial diameter of 5 (SNP5) and $80 \mathrm{~nm}$ (SNP80) (Fig. 1A). Initially, SNP5 and SNP80 were silanized with amine-containing silane compounds (see Materials and methods; named SNP80- $\mathrm{NH}_{2}$ and SNP5- $\mathrm{NH}_{2}$ ) [7]. AmB was immobilized covalently to oxidized dextran (DexOx) by its amine group. Previously, we [7] and others [15] have shown that AmB immobilized by its amine group is still active. The conjugation of $A m B$ to DexOx improves the solubility of $\mathrm{AmB}$ in aqueous solutions and facilitates its immobilization onto SNPs. Then, DexOxAmB $(12 \mathrm{mg} / \mathrm{mL})$ with a degree of $A m B$ incorporation of $15 \%$ was reacted with SNPs. The content of DexOxAmB conjugate immobilized on the surface of NPs was determined by the anthrone assay $[7,16]$. The diameter, net charge, concentration of AmB per mg of SNPs, and minimum inhibitory concentrations (MIC) are summarized in Supplementary Table 1.

\subsection{Internalization of NPS by HUVEC and human skin fibroblasts}

HUVECs and human fibroblasts were chosen in this study as representative models for the various cellular environments that NPs may interact with. Endothelial cells represent a model for the evaluation of NPs toxicity in the bloodstream. Fibroblasts represent a model to evaluate the acute toxicity of the NPs released by the biomedical devices. Initially, the uptake of different sets of fluorescent SNPs by both cells was evaluated by flow cytometry. Both type of cells were exposed to NPs $(50 \mu \mathrm{g} / \mathrm{mL})$ for $5 \mathrm{~h}$ and $24 \mathrm{~h}$ in cell medium containing serum (see Materials and methods). Under these conditions NPs maintain their antifungal properties after incubation in cell medium. HUVECs internalized efficiently all the NPs tested, being approximately $100 \%$ of the cells labeled with NPs after $5 \mathrm{~h}$ (Fig. 1B.1). The internalization of the NPs in HUVECs was also studied for incubation times below $5 \mathrm{~h}$ (Supplementary Fig. $1 \mathrm{~A}$ ). The internalization kinetic of SNP5-DexOxAmB in HUVECs was significantly $(P<0.001$ at $1 \mathrm{~h})$ faster than SNP5-DexOx. Fibroblasts were less prone to internalize NPs as compared to HUVECs (Fig. 1B.2). Fibroblasts internalized with higher efficiency SNP5- $\mathrm{NH}_{2}(5 \mathrm{~h}$ : $82.2 \pm 0.8 \%$; 24 h: $97.6 \pm 0.6 \%$ ) and SNP5-DexOx (5 h: $8.6 \pm 3.2 \%$; $24 \mathrm{~h}: 79.0 \pm 0.9 \%$ ) than SNP5-DexOxAmB ( 5 h: $0.02 \pm 0.03 \% ; 24$ h: $67.2 \pm 2.8 \%$ ). In addition, they internalized with higher efficiency SNP80- $\mathrm{NH}_{2}$ (5 h: $49.5 \pm 0.4 \% ; 24$ h: $86.6 \pm 0.5 \%$ ) and SNP80DexOxAmB ( 5 h: 0\%; 24 h: $75.8 \pm 1.0 \%$ ) than SNP80-DexOx ( 5 h: 0\%; $24 \mathrm{~h}: 63.5 \pm 0.9 \%$ ). Because no substantial differences were observed in the uptake of SNP5 and SNP80 at the $24 \mathrm{~h}$ time point in both types of cells, SNP5 formulation was used for subsequent studies.

To quantify the real amount of NPs internalized by each type of cell, inductive coupled plasma mass spectrometry (ICP-MS) was used (Fig. 1C). For these studies HUVECs and fibroblasts were exposed to SNP5-DexOx and SNP5-DexOxAmB $(50 \mu \mathrm{g} / \mathrm{mL})$ for $5 \mathrm{~h}$ and $24 \mathrm{~h}$. HUVECs internalized higher concentration of NPs (between $36.9 \pm 2.1$ and $65.4 \pm 12.4 \mathrm{pg}$ of $\mathrm{Si}$ per cell) than fibroblasts (between 0 and $2.3 \pm 0.4 \mathrm{pg}$ of Si per cell). In case of HUVECs, the amount of silicon uptake correlates directly with the time of cell exposure to SNPs (Fig. 1C.1). The results indicate a time-dependent increase in the uptake of the SNPs by HUVECs. Our results also show that the conjugation of AmB to the NPs facilitated NP cellular internalization at $24 \mathrm{~h}$.

Very few studies have quantified the real concentration of SNPs internalized by the cells [14]. Typically, the initial dose of NPs added 

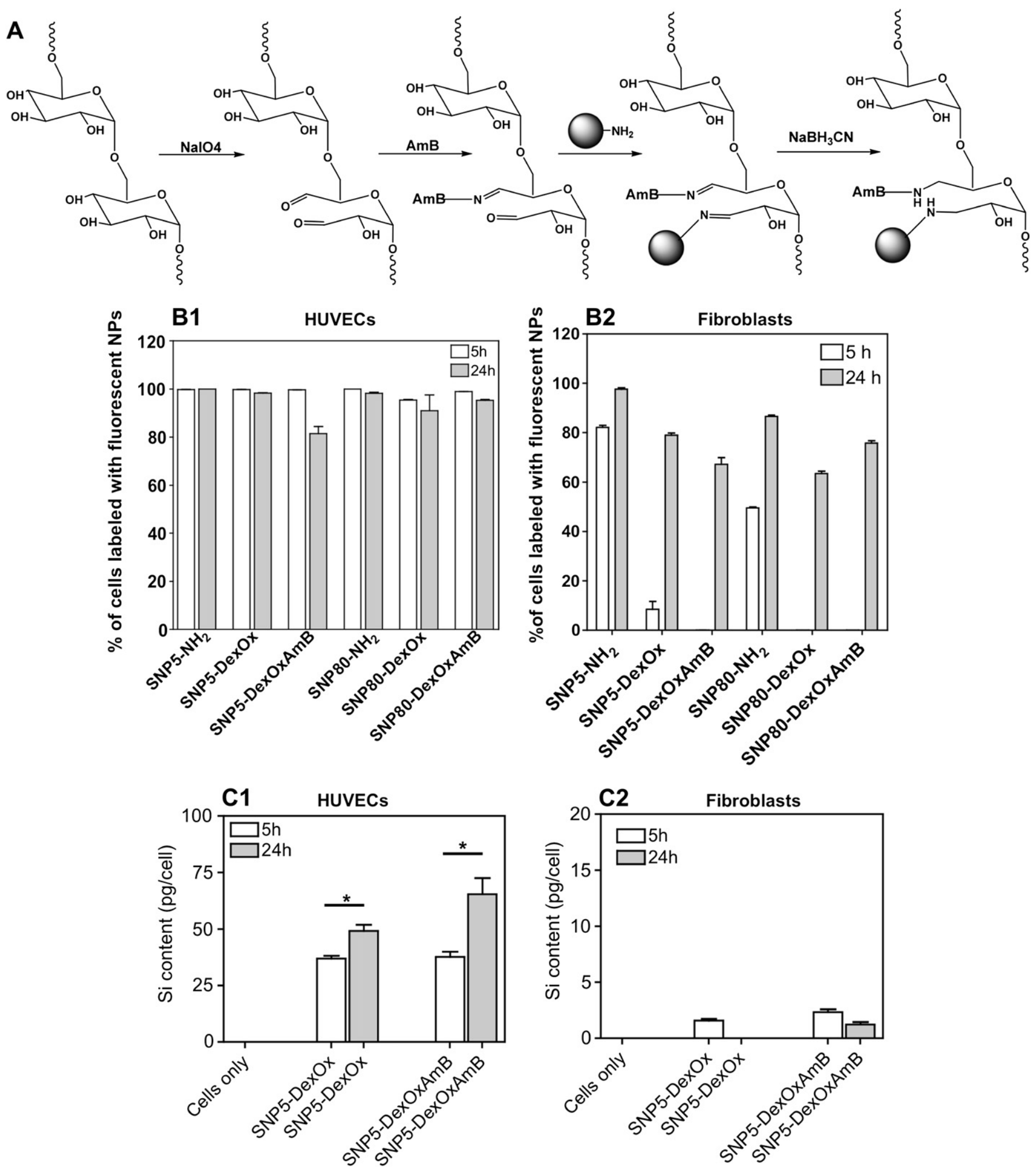

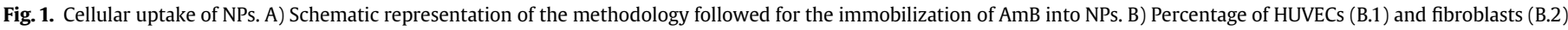

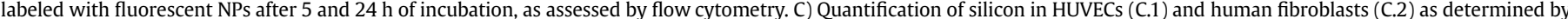

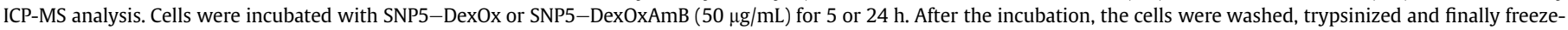
dried. The concentration of silicon was normalized per cell. In B and C, the results are expressed as Mean \pm SEM $(n=3)$. *denotes statistical significance $(P<0.05)$.

to cells is used to evaluate the cytotoxicity of NPs [17,18]. Here, we show that HUVECs have the ability to internalize higher concentrations of SNPs than fibroblasts. The level of internalization obtained for SNP5-DexOx is similar to the one previously reported for
HUVECs ( $40 \mathrm{pg}$ of silicon per cell) exposed for $24 \mathrm{~h}$ to a suspension of SNPs (diameter of $20 \mathrm{~nm}$ ) at $50 \mu \mathrm{g} / \mathrm{mL}$ [14]. To understand the reasons for the differences found between HUVECs and fibroblasts we studied the mechanism of NP internalization. Cells were 
incubated in the presence of endocytosis chemical inhibitors on concentrations that were not cytotoxic for the cells (Supplementary Fig. 2A), after which, fluorescently labeled NPs (SNP5-DexOxAmB and SNP5-DexOx) were added and the internalization monitored by flow cytometry. Filipin III inhibits cholesterol dependent internalization mechanisms [19], nocodazole inhibits microtubule dependent pathways [20], cytochalasin D inhibits all pathways dependent on actin [21], dansylcadaverine inhibits clathrinmediated endocytosis [22] and polyinosinic acid inhibits scavenger receptors [23]. Whenever possible molecules that enter by a specific internalization pathway were used as positive controls to show the efficacy of our inhibitors (Supplementary Fig. 2B). In HUVECs, the response to the inhibitors was similar for both types of NPs (Fig. 2A). Actin filaments mediated the pathway with most impact in the internalization of NPs, since cells inhibited with cytochalasin D had no significant NP internalization. Actin filaments have been shown to be implicated in the mechanisms of clathrin-mediated endocytosis as well as macropinocytosis and formation of circular dorsal ruffles [24]. Our results suggest that macropinocytosis might be the pathway with the highest impact in SNPs internalization since the effect of dansylcadaverine (clathrin inhibitor) was relatively low in NP internalization. In addition, nocodazole had an important inhibitory effect on the internalization of both NPs, implicating microtubules in the uptake mechanism. This agrees with the previous description of microtubules as participants in the mechanism of macropinocytosis [24]. In fibroblasts, cells do not internalize SNP5-DexOxAmB during $5 \mathrm{~h}$ but do SNP5-DexOx (Supplementary Fig. 2C). In this last case, the inhibitory effect of cytochalasin D is similar to the effect of nocodazole, polyinosinic acid and dansylcadaverine, which indicates that macropinocytosis is not the pathway with the highest impact in SNPs internalization. Overall, our results suggest that macropinocytosis seems to be the main internalization route for NPs in HUVEC but not in fibroblasts. Recent studies indicate that HUVECs can internalize carbon nanotubes coated with DNA [25] as well as silicon microparticles [26] by macropinocytosis which indicates that this internalization pathway is not specific for SNPs. The differences in NP internalization on HUVECs and fibroblasts might thus be related to differences in macropinocytosis among cells.

Because the internalization of the NPs by macropinocytosis might be related to the aggregation of the NPs, we studied the size and stability of SNP5-DexOx and SNP5-DexOxAmB in HUVEC culture media (EGM-2 containing $2 \%$ FBS) or fibroblast culture medium (DMEM containing 10\% FBS) by dynamic light scattering (Supplementary Fig. 3). For concentrations of $10 \mu \mathrm{g} / \mathrm{mL}$, the number of NP counts was very low (below $100 \mathrm{kcps}$ ) and therefore not evaluated. For concentrations between 50 and $300 \mu \mathrm{g} / \mathrm{mL} \mathrm{NPs}$ aggregate followed by sedimentation. The aggregation and sedimentation kinetics depend on the initial concentration of the NPs, type of NP and culture medium. Therefore, it is possible that the aggregation of the NPs contribute for the internalization mechanism through macropinocytosis in HUVECs. Overall, our results indicate that HUVECs internalize higher amounts of SNPs, particularly SNP5-DexOxAmB, than fibroblasts and this is likely explained by the fact that HUVECs are more prone to macropinocytosis than fibroblasts.

\subsection{Intracellular accumulation of SNPs conjugated with and without $A m B$}

Confocal microscopy was performed to confirm that SNPs were located intracellularly rather than adsorbing onto the cell surface and to identify the exact intracellular location following internalization. For this purpose, cells were exposed for 5 and $24 \mathrm{~h}$ to fluorescently labeled SNPs (50 $\mu \mathrm{g}$ of NPs per $\mathrm{mL}$ of medium).
Endolysosomes were stained with Lysotracker Red DND-99 and cell membrane stained with anti-human CD31 (for HUVECs; for fibroblasts no marker was used) (Fig. 2 and Supplementary Fig. 4). Images of cells reconstructed from z-stacks of confocal images indicated extensive cellular uptake of NPs, mainly in HUVECs. For both types of cells, after $5 \mathrm{~h}$ of exposure, NPs are mainly observed in the periphery of the cell. At $24 \mathrm{~h}$, the NPs were in general localized in the perinuclear region. This agrees with other reports showing perinuclear accumulation of silica-based nanoparticles in different type of cells [27]. Furthermore, our results show that a significant percentage (HUVECs (24 h)-SNP5-DexOx: $77.6 \pm 15.7 \%$; SNP5DexOxAmB: $99.1 \pm 0.8 \%$; Fibroblasts (24 h)-SNP5-DexOx: $75.9 \pm 34.0 \%$; SNP5-DexOxAmB: $94.1 \pm 8.3 \%$ ) of the NPs were localized in endolysosomes as shown by the co-localization of the NPs with the lysotracker staining (Fig. 2B). We further characterized the cellular uptake of SNPs in HUVECs by transmission electron microscopy (TEM) analyses (Fig. 3). TEM results confirm that either SNP5-DexOx or SNP5-DexOxAmB are taken up by HUVECs and localize within endolysosomal vesicles. Our results also indicate that NPs are taken up by macropinocytosis, with large membrane ruffles engulfing aggregates of NPs (Fig. 3 A.1 and B.2). Overall, our results indicate that most of the NPs that are taken up by both types of cells accumulate in endolysosomal vesicles.

\subsection{Susceptibility of HUVECs and fibroblasts to the cytotoxic effect of SNPs conjugated with AmB}

Previous studies have reported that AmB conjugated to carbon nanotubes had relatively small toxicity towards Jurkat cells, derived from a human T-cell leukemia [5,6]. The cells were incubated up to $16 \mathrm{~h}$ with $\mathrm{AmB}$ conjugated to carbon nanotubes $(10 \mu \mathrm{g} / \mathrm{mL})$. At the end, only $7 \%$ of the cells were apoptotic and $6 \%$ necrotic. However, the concentration of nanotubes within the cells was not quantified and this is important for the evaluation of the cytotoxicity profile of the AmB conjugate. Furthermore, the effect of $A m B$ conjugates on other cell types is still unclear. Although a cell line (such as Jurkat cells) is highly valuable to address questions regarding cytotoxicity, the results should be validated with primary cells [6]. Studies with NPs of different chemical composition suggest that cancer cells are more resistant to NP-mediated toxicity than primary cells found in the human body [14,17].

To assess the biological effect of NPs, cell metabolism and cell proliferation was evaluated after exposing fibroblasts and HUVECs to various concentrations of NPs (from 10 to $500 \mu \mathrm{g} / \mathrm{mL}$ ) for $5 \mathrm{~h}$ and $24 \mathrm{~h}$ (Fig. 4). Cell metabolism was assessed by ATP production. Small effect (between $10 \%$ and 20\%) in ATP production was observed for both type of cells exposed to the NPs for $5 \mathrm{~h}$. However, HUVECs exposed to concentrations equal or higher than $50 \mu \mathrm{g} / \mathrm{mL}$ of SNP5 $-\mathrm{NH}_{2}(50 \mu \mathrm{g} / \mathrm{mL}$ : $62.3 \pm 10.7 \%$ of ATP production relatively to control; $100 \mu \mathrm{g} / \mathrm{mL}: 5.5 \pm 5.2 \%$ ) for $24 \mathrm{~h}$ showed significant impaired ATP production. Similar findings have been reported in a previous study for positively charged silica nanotubes with $200 \mathrm{~nm}$ in length [28]. The nanotubes were cytotoxic for concentrations of $0.5 \mu \mathrm{g} / \mathrm{mL}$ against HUVECs. Here, HUVECs exposed to SNP5-DexOx $(50 \mu \mathrm{g} / \mathrm{mL}: 92.0 \pm 14.6 \%$, relative to control; $100 \mu \mathrm{g} / \mathrm{mL}$ : $75.5 \pm 23.7 \%)$ present significantly less impairment in ATP production $(P<0.0001, n=6)$ than cells exposed to SNP5-DexOxAmB $(50 \mu \mathrm{g} / \mathrm{mL}: 45.1 \pm 10.3 \% ; 100 \mu \mathrm{g} / \mathrm{mL}: 29.8 \pm 6.4 \%)$ for concentrations equal or above $50 \mu \mathrm{g} / \mathrm{mL}$, during $24 \mathrm{~h}$. The effect of NP in cell proliferation was also evaluated. Fibroblast proliferation was not substantially affected in medium containing SNPs up to a concentration of $100 \mu \mathrm{g} / \mathrm{mL}$ (Fig. 4C.2). In contrast, HUVEC proliferation was affected in medium containing SNP5-DexOx or SNP5-DexOxAmB, being highly affected in the last case (Fig. 4C.1). Overall, the results of metabolism and cell proliferation indicate that HUVECs 
A1

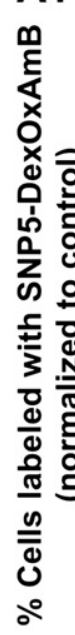

B

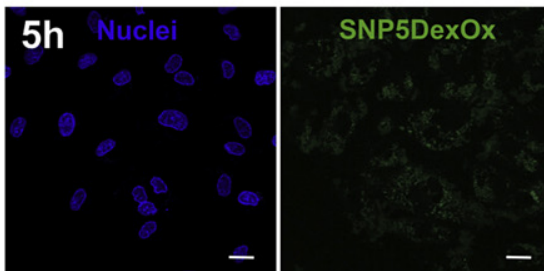

\begin{tabular}{l|l}
\hline Sh Nuclei & SNP5DexOXAmB
\end{tabular}
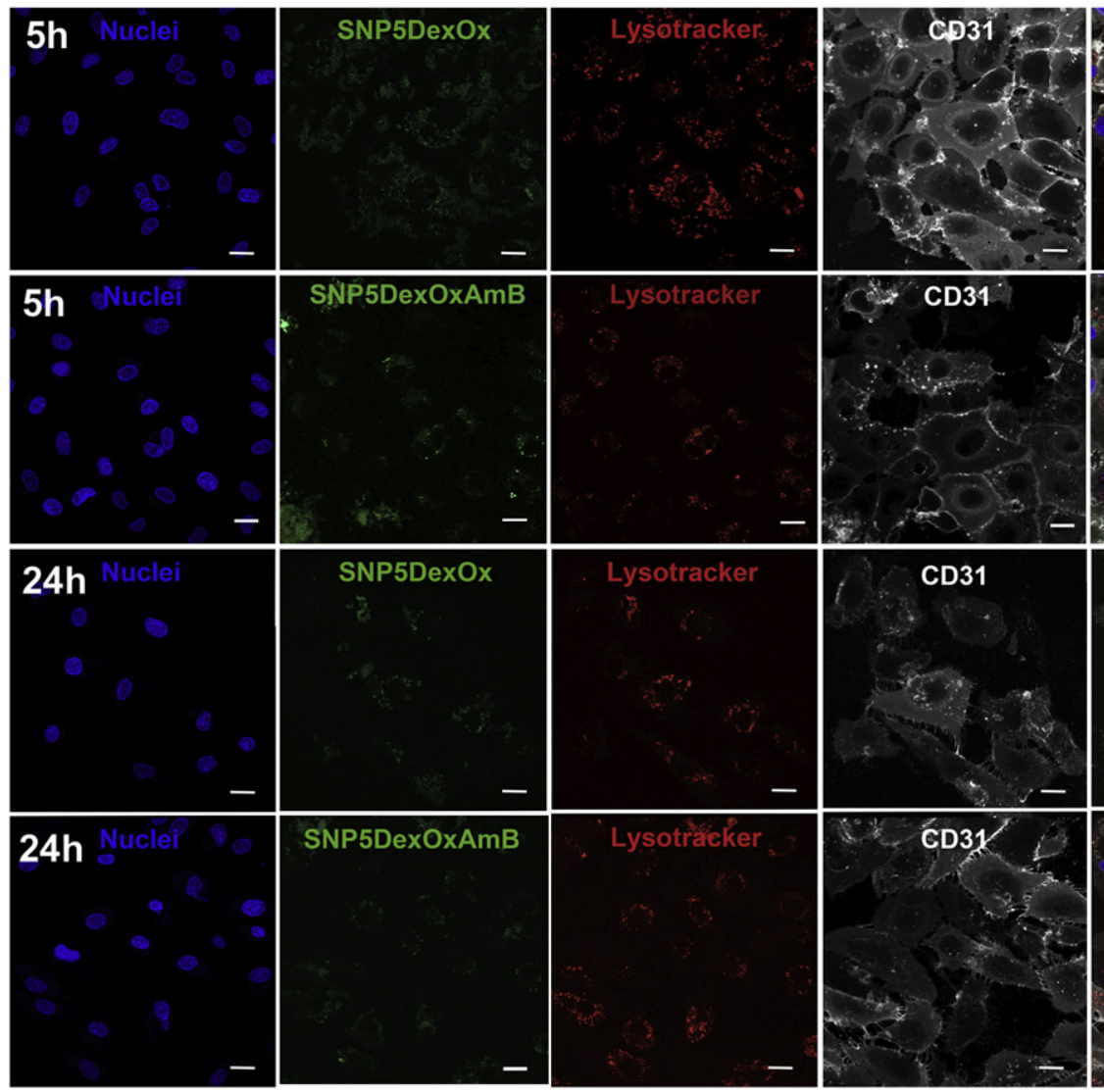
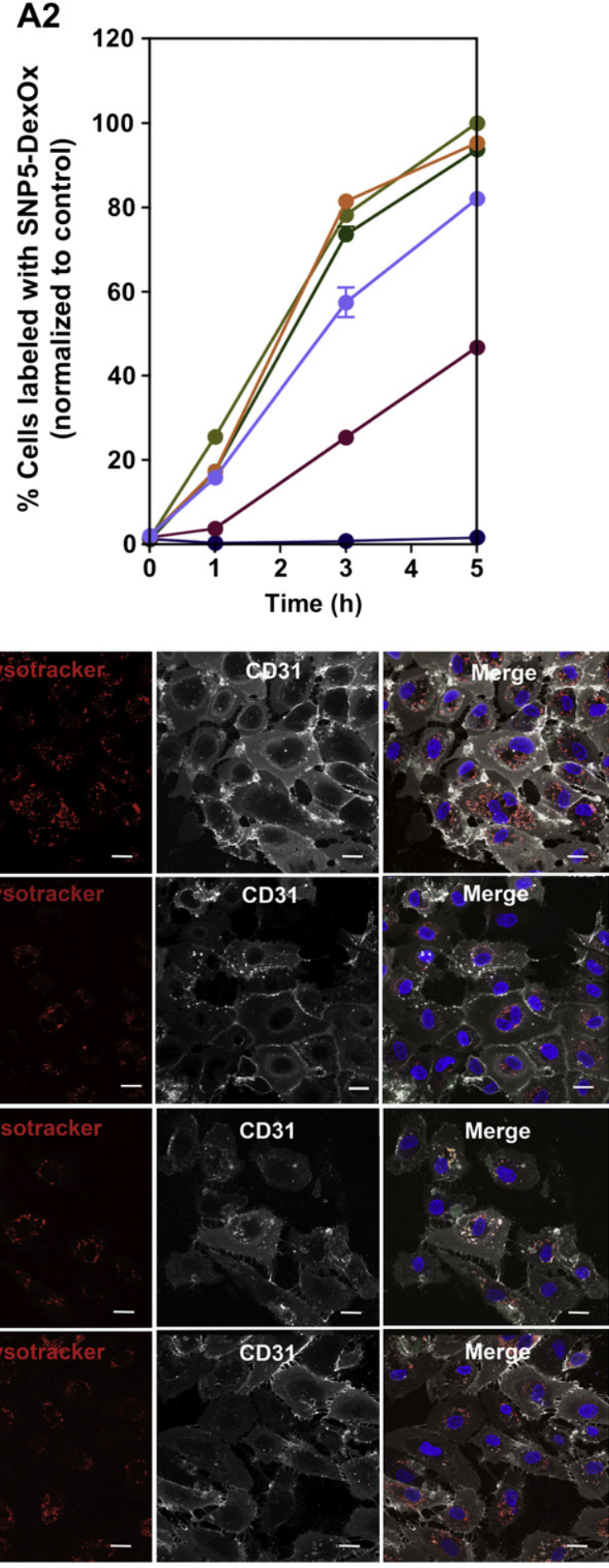

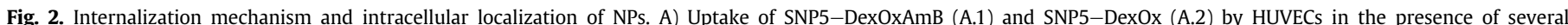

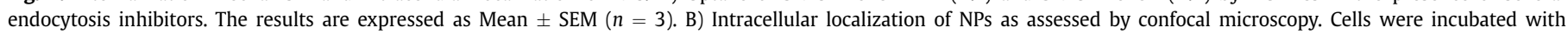

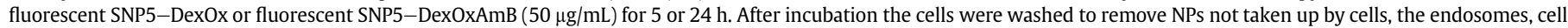
membrane and nuclei were stained with Lysotracker Red DND-99, anti-human CD31 and DAPI, respectively. Bar corresponds to $20 \mu \mathrm{m}$.

are more sensitive to SNPs than fibroblasts. In addition, HUVECs are more sensitive to SNP5-DexOxAmB than SNP5-DexOx indicating that AmB presented by the NPs is cytotoxic.

To determine whether the results obtained by cell metabolism were due to cell death, we exposed HUVECs to SNPs for 5,12 and $24 \mathrm{~h}$ and quantified cell viability/necrosis/apoptosis by flow cytometry using annexin V/PI staining (Fig. 5A). Annexin V is a phospholipid- binding protein with specificity for phosphatidyl serine, one of the earliest markers of cellular transition to an apoptotic state. This phospholipid is translocated from the inner to outer leaflet of the plasma membrane [29]. PI enters necrotic cells and binds to doublestranded nucleic acids, but is excluded from cells with normal integrity [30]. According to Fig. 5A, the viability of HUVECs cultured in medium containing $10 \mu \mathrm{g} / \mathrm{mL}$ of SNP5-DexOxAmB for up to $24 \mathrm{~h}$ 


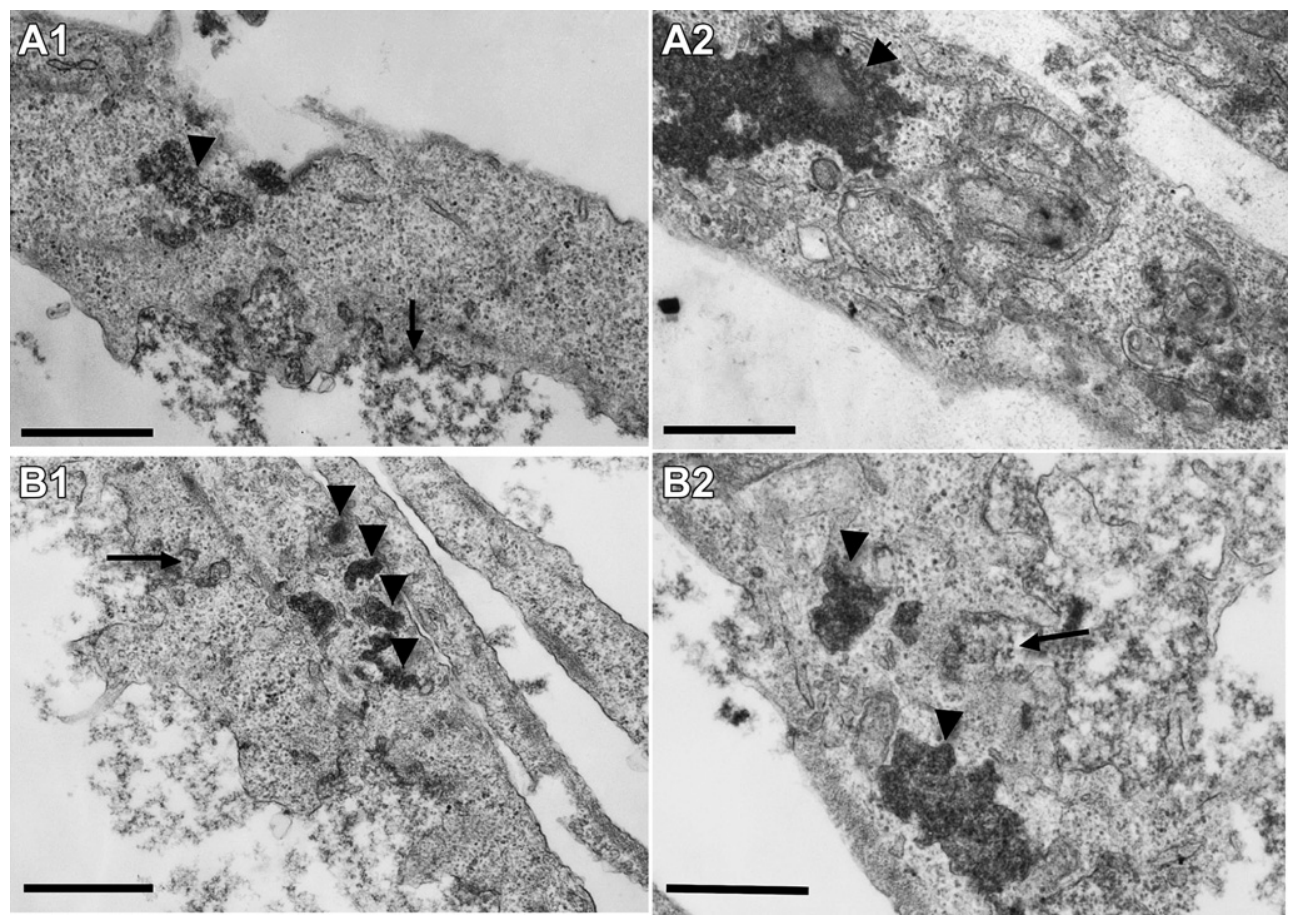

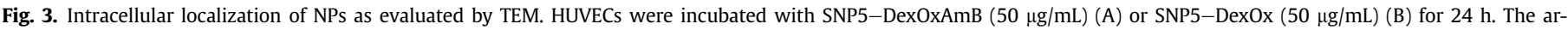
rowheads indicate the presence of endolysosomal compartments. Arrow indicates the presence of sites of NP internalization. Bar corresponds to $1 \mu \mathrm{m}$.

was not statistically different from HUVECs cultured without SNPs (necrosis of $\sim 2 \%$; apoptosis of $\sim 10 \%$ ). However, HUVECs cultured in medium with 50 and $300 \mu \mathrm{g} / \mathrm{mL}$ of SNP5-DexOxAmB show significant levels of necrosis at $5 \mathrm{~h}(50 \mu \mathrm{g} / \mathrm{mL}: 5.1 \pm 2.6 \% ; 300 \mu \mathrm{g} / \mathrm{mL}$ : $61.6 \pm 3.5 \%)$ and $24 \mathrm{~h}(50 \mu \mathrm{g} / \mathrm{mL}: 14.7 \pm 2.7 \% ; 300 \mu \mathrm{g} / \mathrm{mL}$ : $29.7 \pm 4.0 \%$ ), as compared to cells cultured without NPs. This effect was significantly reduced when HUVECs incubated with NPs $(300 \mu \mathrm{g} / \mathrm{mL}$ ) were inhibited with cytochalasin D (macropinocytosis inhibitor, see above) for $5 \mathrm{~h}$ (Supplementary Fig. 1 B). Importantly, for the same concentration, the cellular necrosis was approximately two- or three-fold higher than the one observed on SNP5-DexOx (without $\mathrm{AmB}$ ), showing that $\mathrm{AmB}$ is important in the cytotoxicity profile observed. In contrast to cell necrosis, cell apoptosis was independent of NP concentration. The levels of cell apoptosis (early and late apoptosis) fluctuated along the different concentrations tested, being in most cases below 20\%. These results indicate that necrosis and not apoptosis is the predominant death pathway.

To investigate whether cell death is mediated by loss of cell membrane integrity, lactate dehydrogenase (LDH) leakage was measured (Fig. 5B). HUVECs cultured with SNP5-DexOx (without AmB) up to $300 \mu \mathrm{g} / \mathrm{mL}$ show minimal LDH leakage over $24 \mathrm{~h}$. In contrast, HUVECs cultured in medium containing SNP5-DexOxAmB show high LDH leakage at $5(300 \mu \mathrm{g} / \mathrm{mL}$ ) and $24 \mathrm{~h}$ (concentrations 50,100 and $300 \mu \mathrm{g} / \mathrm{mL}$ ). Overall, our results suggest that for low concentrations of SNP5-DexOxAmB (up to $100 \mu \mathrm{g} / \mathrm{mL}$ ) the NPs are internalized by the cell and only after they contribute for the loss of cell membrane integrity. For high concentrations $(300 \mu \mathrm{g} / \mathrm{mL})$, the overlap between NP internalization and LDH leakage for $5 \mathrm{~h}$ makes it difficult to interpret the results. However, the reduction, but not elimination of observed necrosis for HUVECs cultured in the presence of high concentrations of NPs and cytochalasin D (which completely inhibits NP internalization, see above) indicates that the NPs may also exert a direct cytotoxic effect on the cell membrane.

Overall, our results indicate that HUVECs were more susceptible than fibroblasts to the cytotoxic effect of NPs. This was evaluated by
4 different methodologies: cell metabolism by ATP measurements, cell viability by annexin V/PI staining, cell proliferation and cell membrane integrity by LDH measurements. HUVECs were sensitive to concentrations of $50 \mu \mathrm{g} / \mathrm{mL}$ SNP5-DexOxAmB (at this concentration, no substantial cytotoxic effect was observed for SNP5DexOx) while fibroblasts were resistant to concentrations up to $500 \mu \mathrm{g} / \mathrm{mL}$ of SNP5-DexOxAmB. The low cytotoxicity in fibroblasts is partially due to their low ability to internalize NPs. However, this does not explain all the results since HUVECs inhibited with cytochalasin D (macropinocytosis inhibitor) show cell death (35\%) after $5 \mathrm{~h}$ of exposure to $300 \mu \mathrm{g} / \mathrm{mL}$ of SNP5-DexAmB (not observed in fibroblasts). Therefore, it is likely that differences in the cell membrane composition between HUVECs and fibroblasts might account also for the differences between endothelial and fibroblast cells. The differences in toxicity of soluble AmB between HUVEC and fibroblasts support this hypothesis (Supplementary Fig. 5). Our results show that fibroblasts are less sensitive to soluble AmB than HUVECs. Importantly, the cytotoxic effect of SNP5-DexOxAmB against HUVECs was dependent on its concentration: low concentrations of NPs (up to $100 \mu \mathrm{g} / \mathrm{mL}$ ) were firstly internalized before inducing any cytotoxicity, while high concentrations of NPs (above $100 \mu \mathrm{g} / \mathrm{mL}$ ) induce a rapid cytotoxicity (observed at $5 \mathrm{~h}$ ) likely not mediated by NP internalization. Further, our results show that SNPs conjugated with AmB are more cytotoxic against HUVECs than SNPs without AmB. The results obtained by LDH measurements highlight significant differences in the cytotoxic effect of both NPs. While SNP5-DexOxAmB induce cellular LDH leakage, SNP5DexOx does not have the same effect. This shows that part of the cytotoxic mechanism of AmB in the SNPs is related to its interference with cell membrane integrity.

\subsection{Assessment of oxidative stress in cells cultured with SNPS conjugated with and without AmB}

Previous studies have reported that the cytotoxicity of SNPs is associated with increased oxidative stress. Studies in HUVECs have 

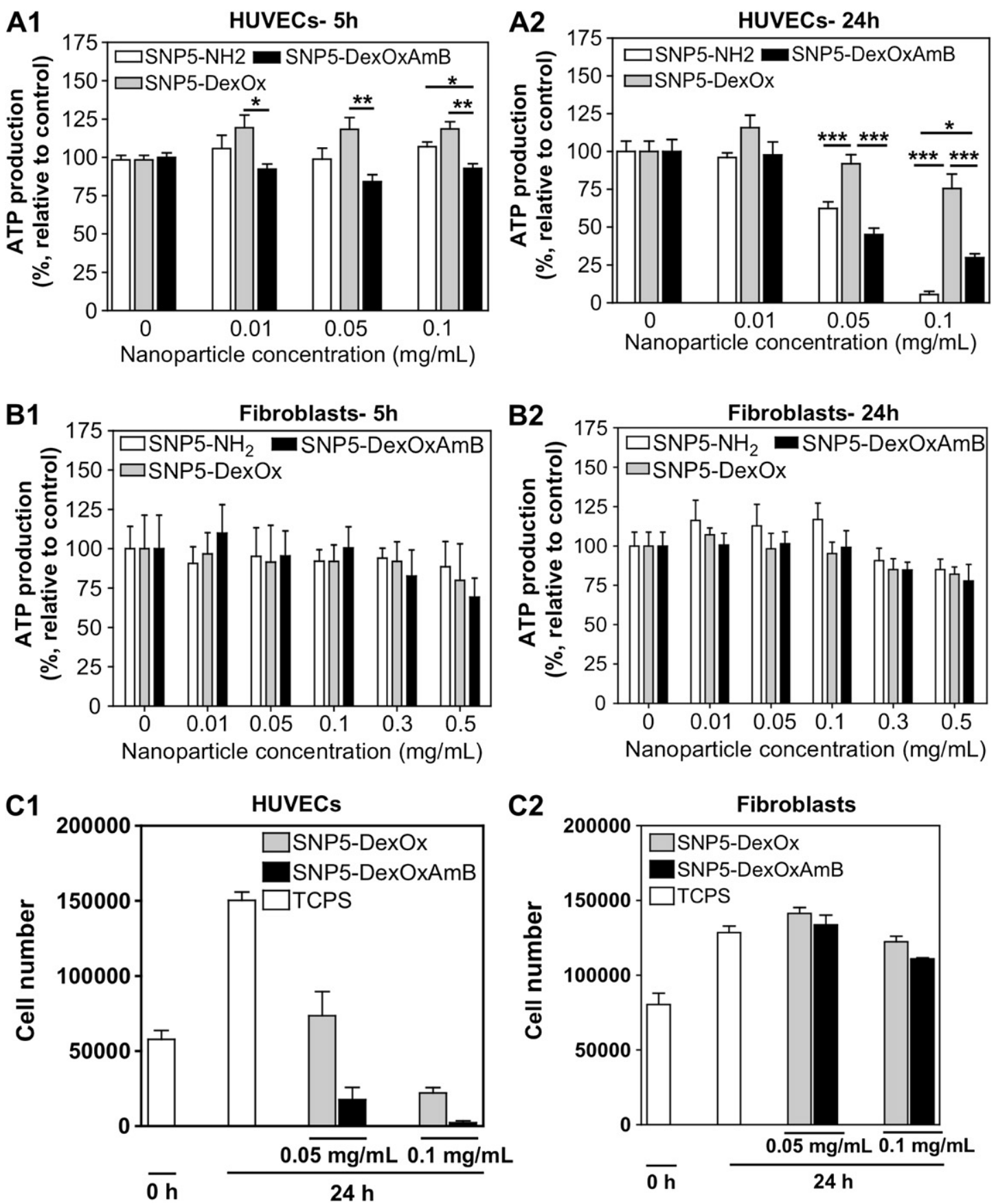

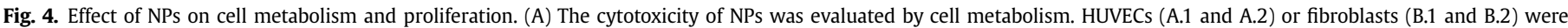

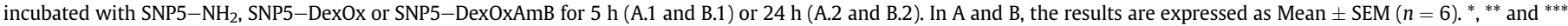

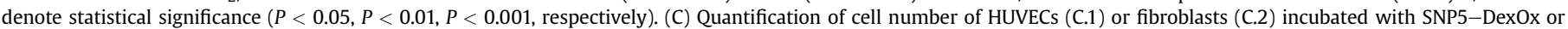
SNP5-DexOxAmB for $24 \mathrm{~h}$. Results are expressed as Mean \pm SEM $(n=3)$. TCPS means cells cultured in tissue culture polystyrene.

shown that SNPs ranging from 50 to $200 \mu \mathrm{g} / \mathrm{mL}$ induce reactive oxygen species (ROS) production, which in turn induce apoptosis, via JNK, p53 and NF- $\mathrm{KB}$ pathways [14]. Furthermore, it has been suggested that AmB increases cellular oxidative stress, specifically lipid peroxidation [2]. To establish the role of oxidative stress in the cytotoxicity of SNPs, carboxy- $\mathrm{H}_{2}$ DCFDA staining was performed and evaluated by flow cytometry (Fig. 5C). In the presence of reactive oxygen species (ROS) fluorescence intensity of the cells stained with this dye increases. HUVECs exposed to SNP5-DexOx give rise to ROS, which increase as a function of SNP intracellular concentration (for 5 and $24 \mathrm{~h}$ ). In contrast, the effect of SNP5DexOxAmB in HUVECs was dependent on its concentration. For small concentrations of SNP5-DexOxAmB (up to $50 \mu \mathrm{g} / \mathrm{mL}$ ) there is production of ROS, while for high concentrations $(300 \mu \mathrm{g} / \mathrm{mL})$ no substantial ROS are produced. These results agree with the twodose dependent effect of SNP5-DexOxAmB described before: low concentrations (up to $50 \mu \mathrm{g} / \mathrm{mL}$ ) are internalized by HUVECs and induce ROS production while high concentrations $(300 \mu \mathrm{g} / \mathrm{mL})$ induce cell membrane damage even in the absence of cell internalization and ROS production. 
A1

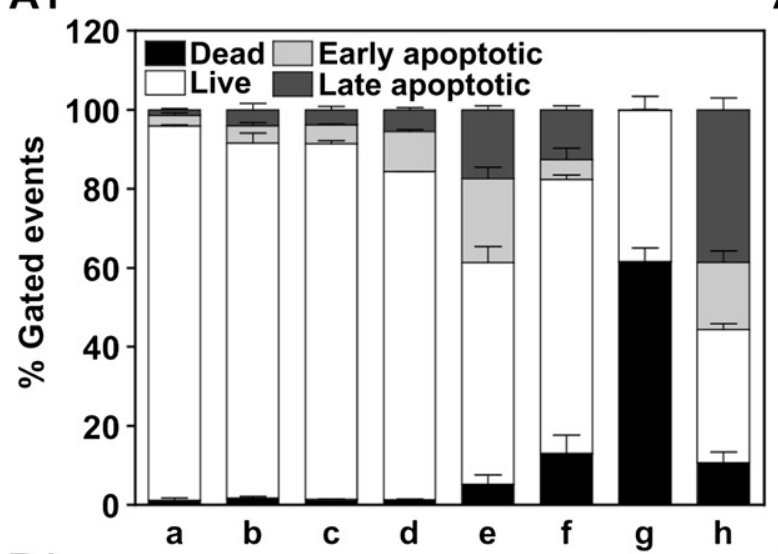

B1

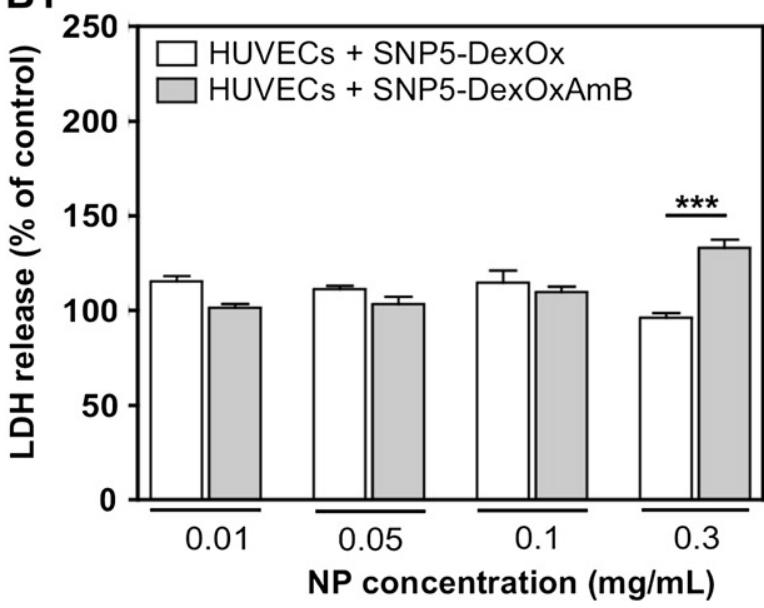

C1

HUVECS

MUHUVEC $+\mathrm{H}_{2} \mathrm{O}_{2}$

HUVECs + SNP5-DexOx

HUVECs + SNP5-DexOxAmB

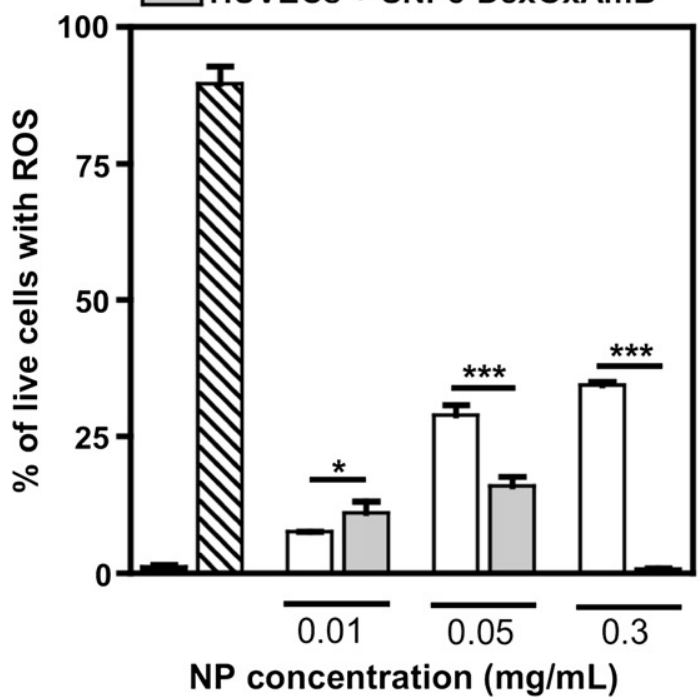

A2

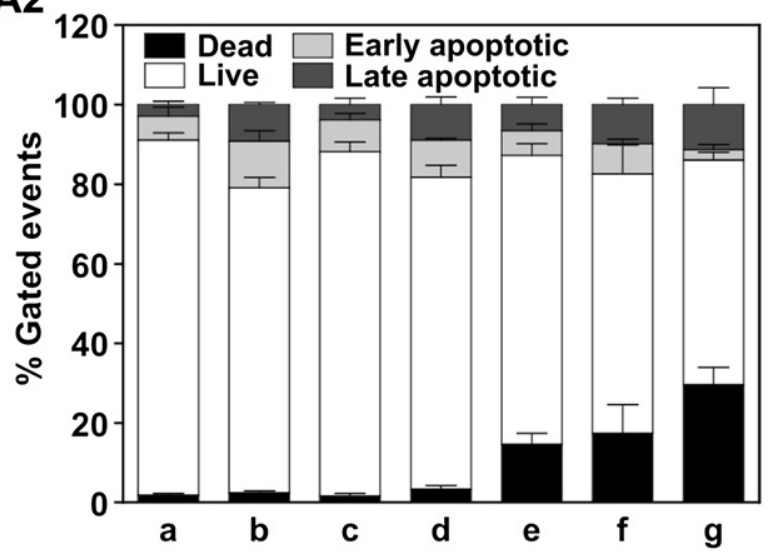

B2

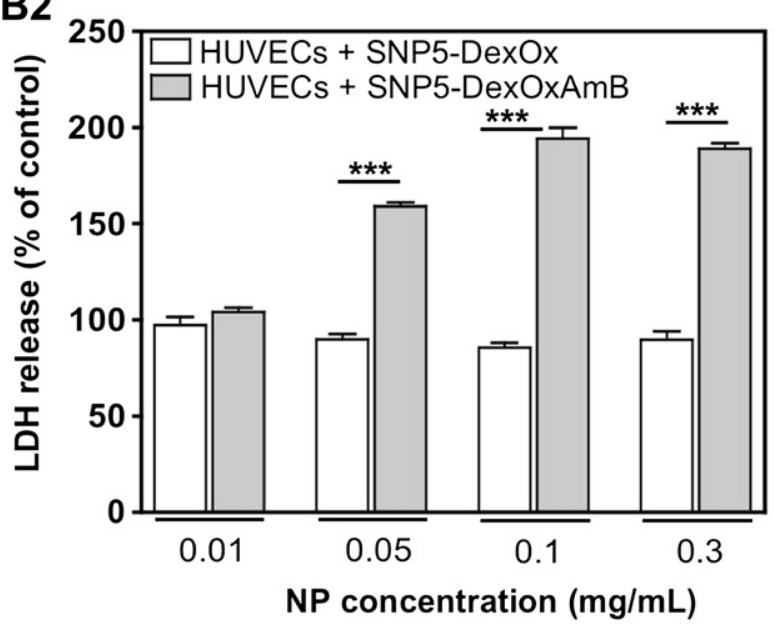

C2

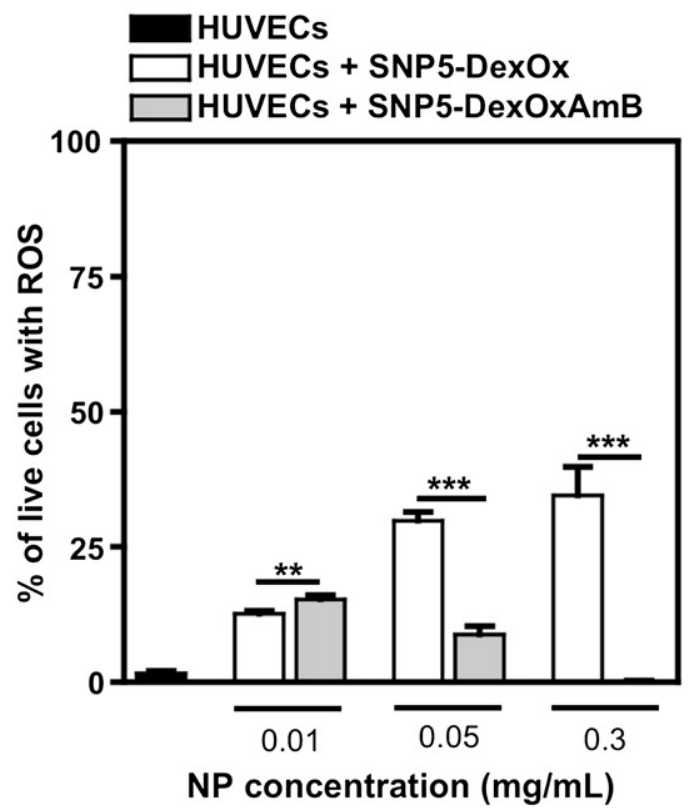

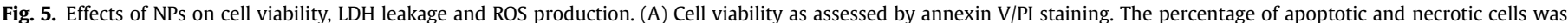

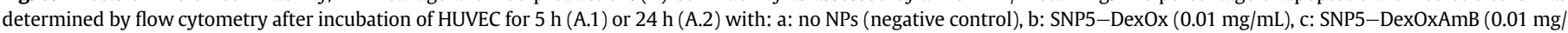

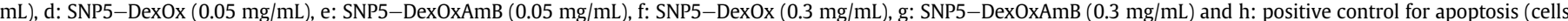

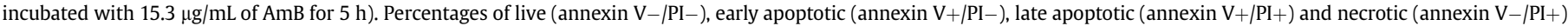

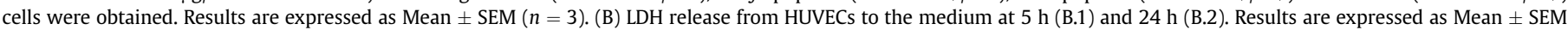

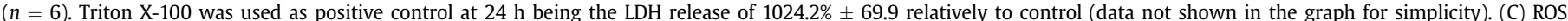

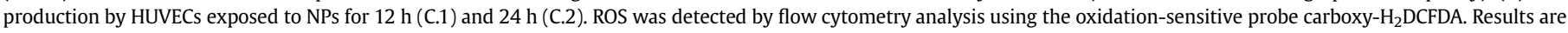
expressed as Mean $\pm \operatorname{SEM}(n=3)$. In all graphs, ${ }^{*},{ }^{* *}$ and ${ }^{* * *}$ denote statistical significance $(P<0.05, P<0.01, P<0.001$, respectively). 
3.6. Expression of pro-inflammatory cytokines by cells treated with SNPs conjugated with and without AmB

Studies in HUVECs have shown that SNPs induce the release of tissue factor, IL-6, IL-8 and MCP-1 [14]. Furthermore, it has been demonstrated that patients that received $\mathrm{AmB}$ have an induction of TNF- $\alpha$, IL-6, IL-1RA and IL-1 $\beta$ [31]. In addition, human innate immune cells cultured with AmB produce high levels of inflammatory cytokines (TNF- $\alpha$, IL-6, IL-1RA and IL-1 $\beta$ ) and chemokines (IL-8, monocyte chemotactic protein- 1 and macrophage inflammatory protein-1 3 ) [32,33]. To evaluate inflammatory response and endothelial/fibroblast activation induced by SNPs, HUVECs or fibroblasts were exposed to the NPs $(50 \mu \mathrm{g} / \mathrm{mL})$ for 5 and $24 \mathrm{~h}$. The collected cell medium was then characterized for the presence of 17 different cytokines using a cytokine bead array (Fig. 6A). For HUVECs and fibroblasts only 4 (MCP-1, IL-8, IL-6 and G-CSF) and 3 (IL-8, IL-6 and MCP-1) cytokines were measurable, respectively. At $5 \mathrm{~h}$, no significant difference $(P>0.05, n=4)$ was observed for all the groups tested, i.e., untreated cells (i.e., cells not exposed to NPs) and cells treated with SNP5-DexOx or SNP5-DexOxAmB. At $24 \mathrm{~h}$, HUVECs exposed to SNP5-DexOxAmB secreted significantly higher levels of IL-8, IL-6 and G-CSF than untreated HUVECs and IL-6 and G-CSF than HUVECs exposed to SNP5-DexOx. Yet, the differences observed in cells treated with SNP5-DexOxAmB and SNP5-DexOx were relatively low. In case of fibroblasts (time $24 \mathrm{~h}$ ), cells secreted similar levels of IL- 6 and MCP- 1 in all the experimental groups tested, but lower levels of IL-8 when treated with SNP5-DexOxAmB than in control $(P<0.01, n=4)$.
A

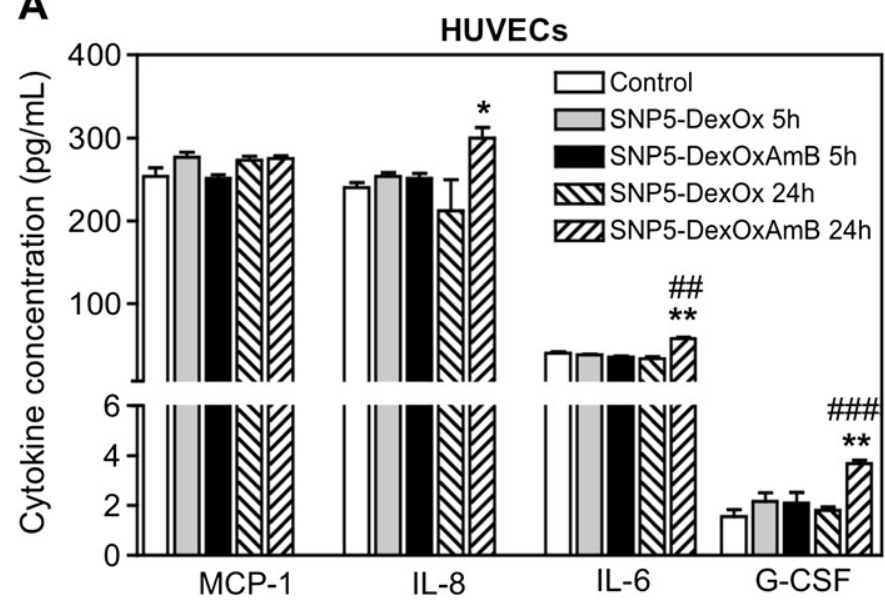

B
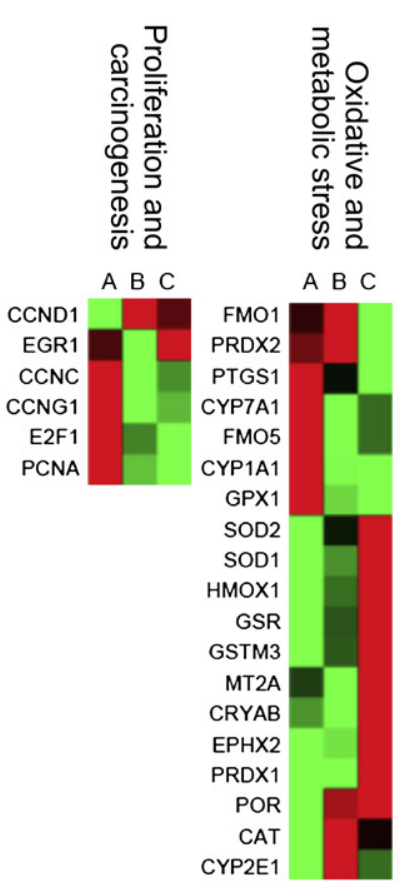
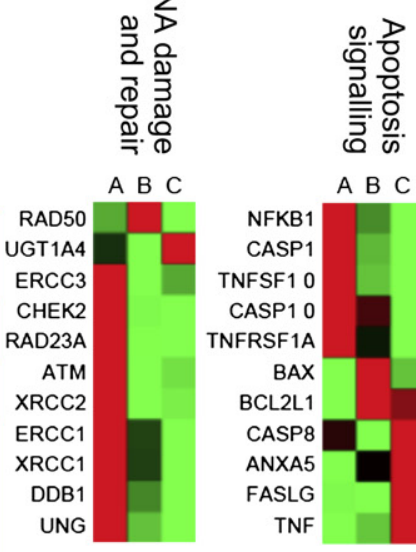

$$
\begin{aligned}
& A=\text { Control } \\
& B=\text { SNP5-DexOx } \\
& C=\text { SNP5-DexOxAmB }
\end{aligned}
$$
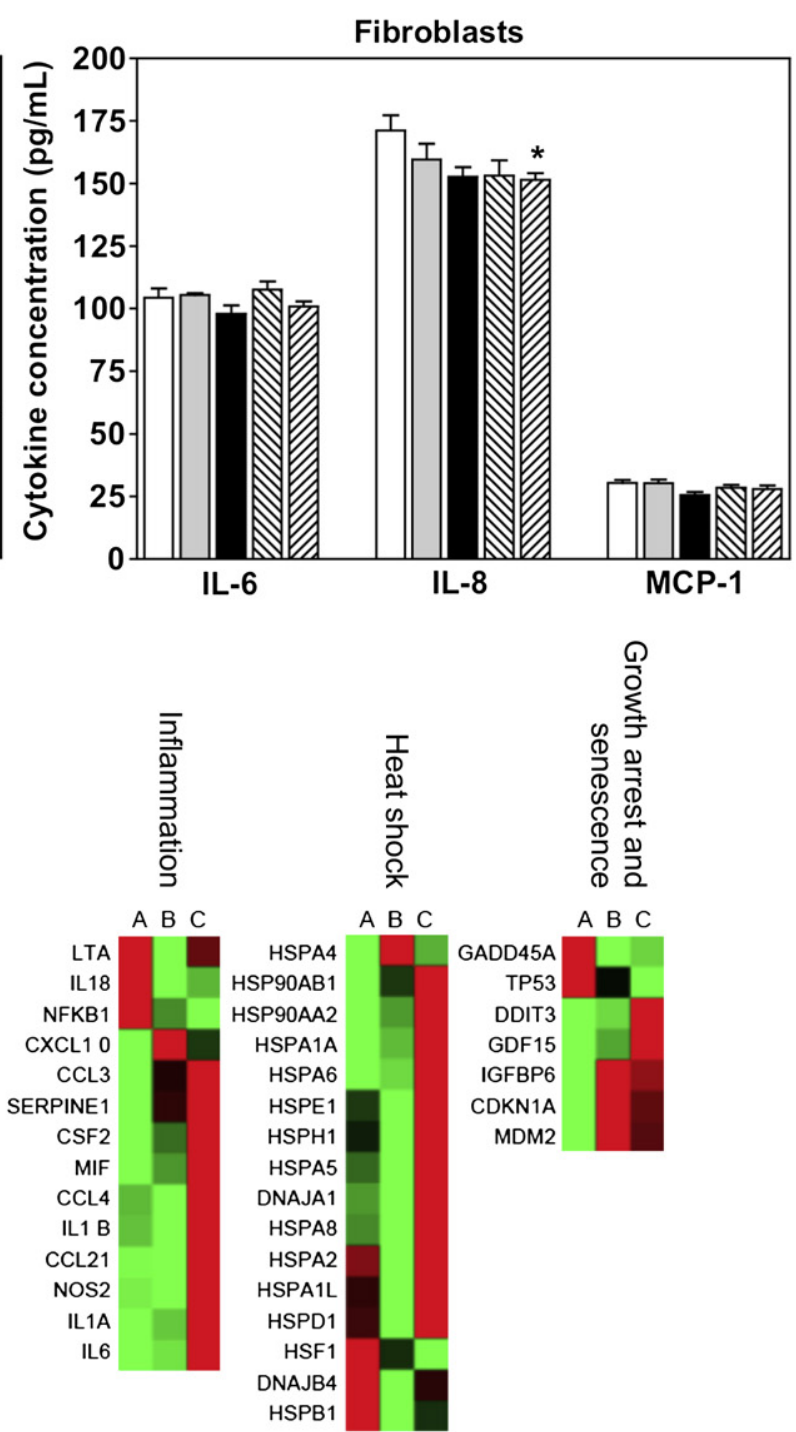

Magnitude of gene expression

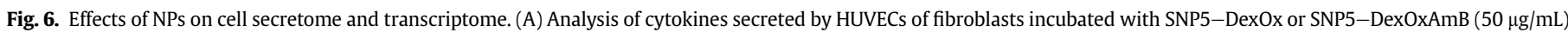

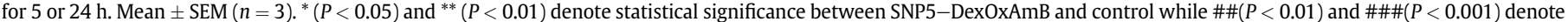

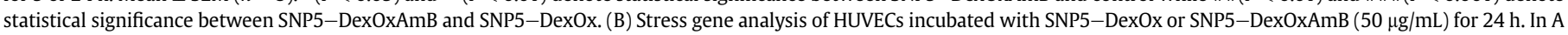
and $\mathrm{B}$, cells incubated in the absence of SNPs were used as control. 

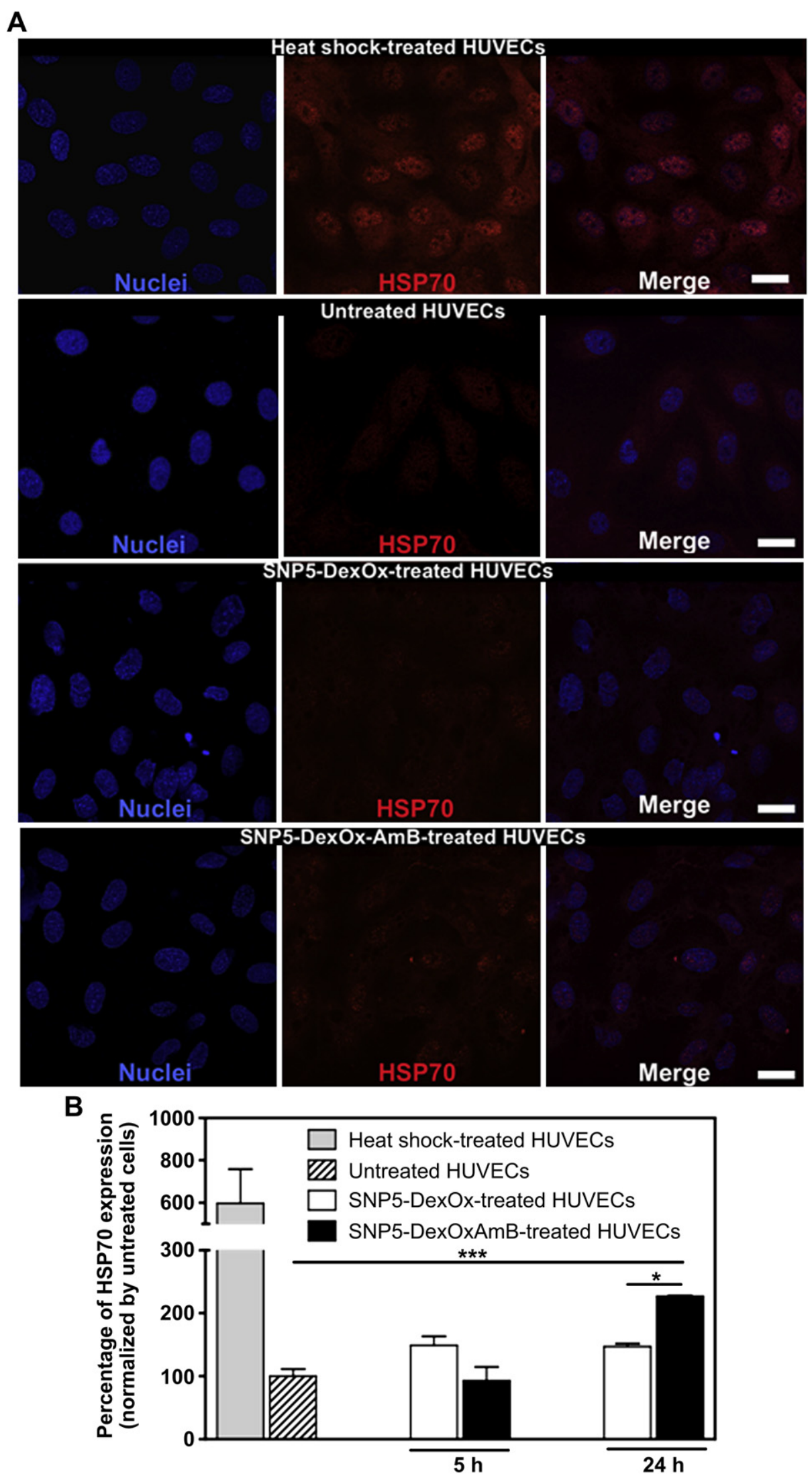

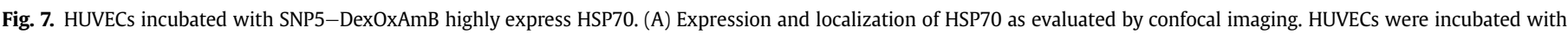

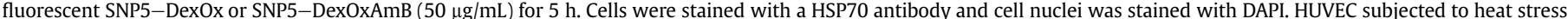

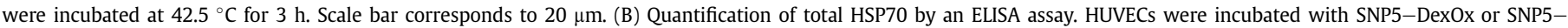

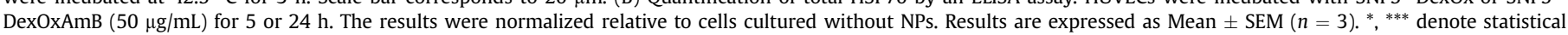
significance $(P<0.05, P<0.001)$. 
3.7. Expression of heat shock proteins (HSPS) by cells treated with SNPs conjugated with and without AmB

To further investigate the cytotoxic effect of SNPs in HUVECs, microarray studies (an array of 90 genes involved in cell apoptosis/ necrosis) were performed to identify differentially expressed genes that may be responsible for the observed cytotoxic profile (Fig. 6B). In some cases, gene expression observed in HUVECs exposed to SNP5-DexOx or SNP5-DexOxAmB was similar, and therefore not related to the presence of AmB. For example, in both cases, HUVECs have a downregulation of genes related to cell proliferation, and an upregulation of genes involved in cell arrest and senescence. This agrees with previous studies showing that cells exposed to certain concentrations of silver NPs [34], gold-based NPs [35], chitosanbased NPs [36], titanium dioxide NPs [37], or gold nanorods [38] have an arrest in cell proliferation (decrease in G1 population accompanied by an increase in $\mathrm{G} 2 / \mathrm{M}$ population). In addition, our results show that HUVECs exposed to NPs have impaired DNA repair mechanisms as compared to untreated cells (cells not exposed to NPs). Only 1 out of 11 genes involved in DNA repair was upregulated in HUVECs exposed to NPs, while in untreated cells 9 out of 11 genes were upregulated (Fig. 6B). The DNA repair machinery involves enzymes, which require energy from ATP to remodel the chromatin $[27,39]$. Therefore, the decrease of ATP in HUVECs exposed to NPs (Fig. 4) likely affected the enzymemediated DNA repair mechanisms, as well as the cascade of events requiring phosphorylation of proteins taking part in the repair of DNA [40]. Moreover, our results show that HUVECs exposed to NPs are more prone to oxidative and metabolic stress. This corroborates previous data showing that SNPs induce oxidative stress in several types of cells [41]. This is likely due to the generation of ROS by SNPs.

Gene arrays revealed significant differences between HUVECs exposed to SNP5-DexOxAmB and SNP5-DexOx in the clusters of genes involved in inflammation and heat shock response (Fig. 6B). HUVECs exposed to SNP5-DexOxAmB are more prone to induce inflammation since 10 out of 14 genes are upregulated. In contrast, in HUVECs exposed to SNP5-DexOx only 1 out of 14 genes is upregulated. From all the genes upregulated in cells exposed to SNP5-DexOxAmB, chemokine (C-C motif) ligand 4 (CCL4), also known as macrophage inflammatory protein $1 \mathrm{~b}$ (MIP-1b), IL-1b and CSF2, also known as granulocyte macrophage colonystimulating factor (GM-CSF), were not observed at protein level (by the cytokine bead array) which may indicate that the concentration secreted was too low (below $1 \mathrm{pg} / \mathrm{mL}$ ) and therefore out of the sensitivity range of the analysis performed, or the genes were not expressed at protein level.

HUVECs exposed to SNP5-DexOxAmB and SNP5-DexOx showed a different profile of expression of genes related to heat shock proteins (Fig. 6B). HUVECs exposed to SNP5-DexOxAmB showed higher expression of genes related to heat shock proteins than cells exposed to SNP5-DexOx. Some of the genes identified in our array encode members of the heat shock protein 10 (HSPE1), 60 (HSPD1), 90 (HSP90AB1; HSP90AA2) and 100 (HSPH1). However, most of the genes encode members of the heat shock protein 70 , namely protein 1A (HSPA1A), protein 1L (HSPA1L), protein 2 (HSPA2), protein 5 (HSPA5), protein 6 (HSPA6) and protein 8 (HSPA8). HSP70 is found in the nucleus and cytoplasm and its role is to help in the folding of nascent proteins and avoid the accumulation of misfolded proteins [42]. This protein is the only one of the family whose transcription is not constitutive, but is highly inducible by high temperatures [43]. Therefore, we used immunofluorescence to monitor the expression and subcellular localization of HSP70 in cells incubated with SNP5-DexOx or SNP5DexOxAmB $(50 \mu \mathrm{g} / \mathrm{mL}$, for 5 or $24 \mathrm{~h}$ ) (Fig. $7 \mathrm{~A})$. The antibody recognizes several members of the heat shock protein $70 \mathrm{kDa}$ (Hsp70) gene family including Hsp70, Hsc70 and p75. Cells without exposure to SNPs or heat stress have a diffuse distribution of HSP70 at the cytoplasm, and at less extent in the nucleus. In contrast, cells exposed to a heat shock at $42.5^{\circ} \mathrm{C}$ for $3 \mathrm{~h}$ have an overall increase in the intensity of fluorescence due to the induced synthesis of HSP70 and an increase in the nuclear localization of HSP70 protein primarily in the phase-dense nucleolar structures. Likewise, cells cultured with SNP5-DexOx or SNP5-DexOxAmB for $5 \mathrm{~h}$ have an increase in the fluorescence intensity and a nuclear localization of HSP70. At 24 h (Supplementary Fig. 6), there is an increase in the fluorescence intensity and nuclear localization of HSP. In this case, spots of HSP70 were also observed at the cell cytoplasm.

The temporal pattern of total HSP70 expression was confirmed quantitatively by an ELISA assay (Fig. 7B). HUVECs exposed to a heat shock have a 6-fold increase in HSP70 content. HUVECs treated with SNP5-DexOx have a slight increase in the expression of HSP70, although not statistically different from the control $(P>0.05, n=3)$. Importantly, HUVECs treated with SNP5-DexOxAmB have a 2-fold increase in HSP70 content relatively to control at $24 \mathrm{~h}$, and the content is statistically different $(P<0.001, n=3)$ to cells exposed to SNP5-DexOx.

Although heat stress is the classic inducer of heat shock proteins, a variety of other stresses including pesticides, heavy metals, and solvents can induce heat shock proteins. Among the various HSP isoforms, HSP70 is often the most representative HSP protein to be expressed following environmental stresses. Indeed the expression of HSP70 has been used as a tool to evaluate the level of toxicity in cells to certain chemicals. However, with the exception of few studies with silver NPs, HSP70 has not been connected with nanotoxicity $[43,44]$. HSP70 is a molecular chaperone that binds to exposed hydrophobic segments of unfolded proteins preventing the formation of protein aggregates and facilitating spontaneous native-protein folding [45]. This protein moves to the nucleus in response to stress. It is believed that the nuclear localization of HSP70 is related to the preservation of ribosomal assembly and function [46]. The increase in the expression of HSP70 in HUVECs treated with SNP5-DexOxAmB as compared to the ones treated with SNP5-DexOx indicates higher stress and protein unfolding.

\section{Conclusions}

Our study demonstrates that the biological impact of AmB immobilized on NPs depends on the cell type. NPs conjugated with AmB are highly internalized by HUVECs but not fibroblasts. Further, the internalization after $24 \mathrm{~h}$ is higher for HUVECs exposed to NPs conjugated with AmB than without AmB. The internalization process in HUVECs is mainly mediated by macropinocytosis, while in fibroblasts the internalization is mediated by different pathways. In both type of cells, the NPs accumulate primarily in the endolysosomal compartment. Our study also demonstrates that the cytotoxic profile of NPs conjugated with AmB is negligible on fibroblasts for concentrations up to $400 \mu \mathrm{g} / \mathrm{mL}$ while for HUVECs depend in the NP concentration. For concentrations of SNP5-DexOxAmB up to $10 \mu \mathrm{g} / \mathrm{mL}$ they are non-cytotoxic. For concentrations between 10 and $100 \mu \mathrm{g} / \mathrm{mL}$ the cytotoxic effect is mediated by the production of ROS. There is (i) cell death (approximately $70 \%$ of the initial cells after $24 \mathrm{~h}$ for a concentration of $50 \mu \mathrm{g} / \mathrm{mL}$ ), (ii) LDH release after $24 \mathrm{~h}$ of exposure to NPs, (iii) high expression of pro-inflammatory cytokines and chemokines (IL-8, IL-6, G-CSF, CCL4, IL-1 $\beta$ and CSF2), (iv) high expression of genes related to heat shock proteins, and (v) an increase in the expression of HSP70 at protein level. For concentrations of SNP5-DexOxAmB above $100 \mu \mathrm{g} / \mathrm{mL}$ the cytotoxic effect is mediated by cell permeabilization. This is confirmed by the 
absence of ROS and an increase in the release of LDH. Sixty percent of the initial cells are dead after $5 \mathrm{~h}$.

\section{Acknowledgments}

The authors would like to thank the financial support of Fundação para a Ciência e a Tecnologia (SFRH/BD/35270/2007; fellowship to C. P.; PTDC/Qui-Qui/105000/2008), Matera [QREN (project $\mathrm{n}^{\circ}$ 5402)] and the MIT-Portugal Program (focus in Bioengineering). The authors would like to thank Mario Grãos (Biocant) for the cytokine analyses, Olga Borges and Sandra Jesus (both from the Center for Neuroscience and Cell Biology) in the detection of endotoxin levels in the NPs.

\section{Appendix A. Supplementary data}

Supplementary data related to this article can be found at http:// dx.doi.org/10.1016/j.biomaterials.2013.03.048.

\section{References}

[1] Torrado JJ, Espada R, Ballesteros MP, Torrado-Santiago S. Amphotericin B formulations and drug targeting. J Pharm Sci 2008;97:2405-25.

[2] Brajtburg J, Powderly WG, Kobayashi GS, Medoff G. Amphotericin B: current understanding of mechanisms of action. Antimicrob Agents Chemother 1990;34:183-8.

[3] Hudson SP, Langer R, Fink GR, Kohane DS. Injectable in situ cross-linking hydrogels for local antifungal therapy. Biomaterials 2010;31:1444-52.

[4] Zumbuehl A, Ferreira L, Kuhn D, Astashkina A, Long L, Yeo Y, et al. Antifungal hydrogels. Proc Natl Acad Sci U S A 2007;104:12994-8.

[5] Wu W, Wieckowski S, Pastorin G, Benincasa M, Klumpp C, Briand JP, et al. Targeted delivery of amphotericin B to cells by using functionalized carbon nanotubes. Angew Chem Int Ed Engl 2005;44:6358-62.

[6] Benincasa M, Pacor S, Wu W, Prato M, Bianco A, Gennaro R. Antifungal activity of amphotericin B conjugated to carbon nanotubes. ACS Nano 2011;5:199-208.

[7] Paulo CS, Vidal M, Ferreira LS. Antifungal nanoparticles and surfaces. Biomacromolecules 2010;11:2810-7.

[8] Wasan KM, Rosenblum MG, Cheung L, Lopez-Berestein G. Influence of lipoproteins on renal cytotoxicity and antifungal activity of amphotericin B. Antimicrob Agents Chemother 1994;38:223-7.

[9] Wasan KM, Conklin JS. Enhanced amphotericin B nephrotoxicity in intensive care patients with elevated levels of low-density lipoprotein cholesterol. Clin Infect Dis 1997;24:78-80.

[10] Meletiadis J, Chanock S, Walsh TJ. Defining targets for investigating the pharmacogenomics of adverse drug reactions to antifungal agents. Pharmacogenomics 2008;9:561-84.

11] Hsu S, Burnette RR. Characterization of the effects of amphotericin B on ion channels in MDCK cells using the patch-clamp technique. Biochim Biophys Acta 1997; 1329:26-38.

[12] Brito LA, Singh M. Acceptable levels of endotoxin in vaccine formulations during preclinical research. J Pharm Sci 2011;100:34-7.

[13] McNeer NA, Chin JY, Schleifman EB, Fields RJ, Glazer PM, Saltzman WM. Nanoparticles deliver triplex-forming PNAs for site-specific genomic recombination in CD34+ human hematopoietic progenitors. Mol Ther 2011;19:172-80.

[14] Liu X, Sun J. Endothelial cells dysfunction induced by silica nanoparticles through oxidative stress via JNK/P53 and NF-kappaB pathways. Biomaterials 2010;31:8198-209.

[15] Ehrenfreund-Kleinman T, Azzam T, Falk R, Polacheck I, Golenser J, Domb AJ Synthesis and characterization of novel water soluble amphotericin B-arabinogalactan conjugates. Biomaterials 2002;23:1327-35.

[16] Shields R, Burnett W. Determination of protein-bound carbohydrate in serum by a modified anthrone method. Anal Chem 1960;32:885-6.

[17] Chang JS, Chang KL, Hwang DF, Kong ZL. In vitro cytotoxicitiy of silica nanoparticles at high concentrations strongly depends on the metabolic activity type of the cell line. Environ Sci Technol 2007;41:2064-8.

[18] Napierska D, Thomassen LC, Rabolli V, Lison D, Gonzalez L, Kirsch-Volders M, et al. Size-dependent cytotoxicity of monodisperse silica nanoparticles in human endothelial cells. Small 2009;5:846-53.

[19] Kaiser RA, Oxhorn BC, Andrews G, Buxton ILO. Functional compartmentation of endothelial P2Y receptor signaling. Circ Res 2002;91:292-9.
[20] dos Santos T, Varela J, Lynch I, Salvati A, Dawson KA. Effects of transport inhibitors on the cellular uptake of carboxylated polystyrene nanoparticles in different cell lines. PLoS One 2011;6:10.

[21] Fujimoto LM, Roth R, Heuser JE, Schmid SL. Actin assembly plays a variable, but not obligatory role in receptor-mediated endocytosis in mammalian cells. Traffic 2000;1:161-71.

[22] Lunov O, Syrovets T, Loos C, Beil J, Delecher M, Tron K, et al. Differential uptake of functionalized polystyrene nanoparticles by human macrophages and a monocytic cell line. ACS Nano 2011;5:1657-69.

[23] Adachi H, Tsujimoto M, Arai H, Inoue K. Expression cloning of a novel scavenger receptor from human endothelial cells. J Biol Chem 1997;272:31217-20.

[24] Doherty GJ, McMahon HT. Mechanisms of endocytosis. Annu Rev Biochem 2009:857-902.

[25] Bhattacharya S, Roxbury D, Gong X, Mukhopadhyay D, Jagota A. DNA conjugated SWCNTs enter endothelial cells via Rac1 mediated macropinocytosis. Nano Lett 2012;12:1826-30.

[26] Serda RE, Gu J, Bhavane RC, Liu X, Chiappini C, Decuzzi P, et al. The association of silicon microparticles with endothelial cells in drug delivery to the vasculature. Biomaterials 2009;30:2440-8.

[27] Bale SS, Kwon SJ, Shah DA, Banerjee A, Dordick JS, Kane RS. Nanoparticlemediated cytoplasmic delivery of proteins to target cellular machinery. ACS Nano 2010;4:1493-500.

[28] Nan A, Bai X, Son SJ, Lee SB, Ghandehari H. Cellular uptake and cytotoxicity of silica nanotubes. Nano Lett 2008;8:2150-4.

[29] Koopman G, Reutelingsperger CP, Kuijten GA, Keehnen RM, Pals ST, van Oers $\mathrm{MH}$. Annexin V for flow cytometric detection of phosphatidylserine expression on B cells undergoing apoptosis. Blood 1994;84:1415-20.

[30] Waring MJ. Complex formation between ethidium bromide and nucleic acids. J Mol Biol 1965;13:269-82.

[31] Arning $\mathrm{M}$, Kliche $\mathrm{KO}$, Heer-Sonderhoff $\mathrm{AH}$, Wehmeier A. Infusion-related toxicity of three different amphotericin B formulations and its relation to cytokine plasma levels. Mycoses 1995;38:459-65.

[32] Rogers PD, Pearson MM, Cleary JD, Sullivan DC, Chapman SW. Differential expression of genes encoding immunomodulatory proteins in response to amphotericin B in human mononuclear cells identified by cDNA microarray analysis. J Antimicrob Chemother 2002;50:811-7.

[33] Simitsopoulou M, Roilides E, Dotis J, Dalakiouridou M, Dudkova F, Andreadou E, et al. Differential expression of cytokines and chemokines in human monocytes induced by lipid formulations of amphotericin B. Antimicrob Agents Chemother 2005;49:1397-403.

[34] AshaRani PV, Low Kah Mun G, Hande MP, Valiyaveettil S. Cytotoxicity and genotoxicity of silver nanoparticles in human cells. ACS Nano 2009;3:279-90.

[35] Roa W, Zhang X, Guo L, Shaw A, Hu X, Xiong Y, et al. Gold nanoparticle sensitize radiotherapy of prostate cancer cells by regulation of the cell cycle. Nanotechnology 2009;20.

[36] Luo H, Su H, Wang X, Wang L, Li J. N-Succinyl-chitosan nanoparticles induced mitochondria-dependent apoptosis in K562. Mol Cell Probes 2012;26:164-9.

[37] Wu J, Sun J, Xue Y. Involvement of JNK and P53 activation in G2/M cell cycle arrest and apoptosis induced by titanium dioxide nanoparticles in neuron cells. Toxicol Lett 2010;199:269-76.

[38] Xu W, Luo T, Li P, Zhou C, Cui D, Pang B, et al. RGD-conjugated gold nanorods induce radiosensitization in melanoma cancer cells by downregulating alpha(v)beta(3) expression. Int J Nanomed 2012;7:915-24.

[39] Ferreira L, Squier T, Park H, Choe H, Kohane DS, Langer R. Human embryoid bodies containing nano- and micro-particulate delivery vehicles. Adv Mater 2008;20:2285-91

[40] Voyta JC, Via DP, Butterfield CE, Zetter BR. Identification and isolation of endothelial cells based on their increased uptake of acetylated-Low density lypoprotein. J Cell Biol 1984;99:2034-40.

[41] Dutta D, Sundaram SK, Teeguarden JG, Riley BJ, Fifield LS, Jacobs JM, et al. Adsorbed proteins influence the biological activity and molecular targeting of nanomaterials. Toxicol Sci 2007:100:303-15.

[42] Bhattacharyya T, Karnezis AN, Murphy SP, Hoang T, Freeman BC, Phillips B, et al. Cloning and subcellular-localization of human mitochondrial Hsp70. J Biol Chem 1995;270:1705-10.

[43] Ahamed M, Posgai R, Gorey TJ, Nielsen M, Hussain SM, Rowe JJ. Silver nanoparticles induced heat shock protein 70 , oxidative stress and apoptosis in Drosophila melanogaster. Toxicol Appl Pharmacol 2010;242:263-9.

[44] Lim DH, Jang J, Kim S, Kang T, Lee K, Choi IH. The effects of sub-lethal concentrations of silver nanoparticles on inflammatory and stress genes in human macrophages using cDNA microarray analysis. Biomaterials 2012;33: 4690-9.

[45] Goloubinoff P, De Los Rios P. The mechanism of Hsp70 chaperones: (entropic) pulling the models together. Trends Biochem Sci 2007;32:372-80.

[46] Welch WJ, Feramisco JR. Nuclear and nucleolar localization of the 72,000dalton heat shock protein in heat-shocked mammalian cells. J Biol Chem 1984;259:4501-13. 